Randomized Trial

\title{
Clinical Outcomes of Posterolateral Fusion Versus Posterior Lumbar Interbody Fusion in Patients with Lumbar Spinal Stenosis and Degenerative Instability
}

Majid Reza Farrokhi, MD², Golnaz Yadollahikhales, MD ${ }^{1,3}$, Mehrnaz Gholami, MA', Seyed Reza Mousavi, MD1', Amir Reza Mesbahi, MD, and Ali A. Asadi-Pooya, MD,5

From: ${ }^{\text {Sh }}$ iraz Neuroscience Research Center, Shiraz University of Medical Sciences, Shiraz, Iran; ${ }^{2}$ Department of Neurosurgery, Shiraz University of Medical Sciences, Shiraz, Iran; 3University of Illinois at Chicago, Department of Neurology, Chicago, Illinois, USA; ${ }^{4}$ Orthopedic Department,

Shiraz University of Medical

Sciences, Shiraz, Iran; 5 Jefferson Comprehensive Epilepsy Center,

Department of Neurology,

Thomas Jefferson University, Philadelphia, PA, USA

Address Correspondence: Majid Reza Farrokhi, MD Professor of Neurosurgery

Shiraz Neuroscience Research Center, Department of

Neurosurgery, Shiraz University of Medical Sciences P.O. Box 7194815644 Shiraz, Iran E-mail:

farrokhimr@yahoo.com

Disclaimer: There was no external funding in the preparation of this manuscript.

Conflict of interest: Each author certifies that he or she, or a member of his or her immediate family, has no commercial association (i.e., consultancies, stock ownership, equity interest, patent/licensing arrangements, etc.) that might pose a conflict of interest in connection with the submitted manuscript.

Manuscript received: 11-29-2017

Revised manuscript received: 01-31-2018

Accepted for publication: 02-02-2018

Free full manuscript: www.painphysicianjournal.com
Background: Degenerative lumbar spine disease can lead to lumbar spine instability. Lumbar spine instability is defined as an abnormal response to applied loads characterized kinematically by abnormal movement in the motion segment beyond normal constraints. Patients with lumbar spinal stenosis (LSS) typically present with low back pain (LBP), cramping, cauda equine syndrome, and signs of nerve root compression associated by weakness, numbness and tingling in their legs that are worsened with standing and walking. This degenerative condition severely restricts function, walking ability, and quality of life (QOL).

Objectives: This study aims to compare clinical and radiological outcomes of posterolateral fusion (PLF) with posterior lumbar interbody fusion (PLIF) with posterior instrumentation in the treatment of LSS and degenerative instability.

Study Design: A randomized, prospective, controlled clinical study.

Methods: In this prospective study, 88 patients with LSS and degenerative instability were randomly allocated to one of 2 groups: PLF (Group I) or PLIF (Group II). Primary outcomes were the control of LBP and radicular pain, evaluated with visual analog scale (VAS), the improvement of QOL assessed by the Oswestry disability index (ODI) scale, and measurement of fusion rate, Cobb angle, spinal sagittal balance, and modic changes in the 2 groups.

Results: At 24 months postoperatively, the mean reduction in VAS scores in Group I was more than in Group II (5.67 vs. 5.48, respectively) and the patients in Group I had more improvement in the ODI score than the patients in Group II (42.75 vs. 40.94, respectively). There was a statistically significant difference between the preoperative and postoperative sagittal balance in the 2 groups. The mean Cobb angle changed significantly in the 2 groups.

Limitations: There are few prospective studies of PLIF or PLF in patients with LSS and degenerative lumbar spine instability, and a limited number of studies which exists have examined the safety and outcome of each procedure without comparing it with other fusion techniques. Because most of the studies in the literature have been conducted in the patients with IS, we could not compare and contrast our findings with studies in patients with LSS and degenerative lumbar spine instability. In addition, although in our study the findings at a 24-month follow-up period showed that PLF was better than PLIF in these patients, there were some studies in which the authors reported that PLIF showed better clinical results than PLF at a 48-month followup period. So we suggest that rigorous controlled trials at longer follow-up periods should be undertaken in groups of patients with LSS and degenerative lumbar spine instability who undergo posterior decompression and instrumented fusion to help to determine the ultimate best fusion technique for these patients.

Conclusion: PLF with posterior instrumentation provides better clinical outcomes and improvement in the $\mathrm{LBP}$, radicular pain, and functional QOL, more correction of the Cobb angle, more restoration of sagittal alignment, more decrease in Modic type 1, and more increase in Modic type 0 , despite the low fusion rate compared to PLIF.

Key words: Lumbar spinal stenosis, degenerative instability, posterolateral fusion, posterior lumbar interbody fusion, low back pain, quality of life, cobb angle, fusion rate, mobic changes, sagittal balance

Pain Physician 2018: 21:383-406 
umbar spine instability is defined as an abnormal response to applied loads characterized kinematically by abnormal movement in the motion segment beyond normal constraints (1). This abnormal response is due to damage to restraints that hold the spine in stable position (1). Upright posture and upright weight bearing in humans cause excess stresses that are maximal at and suprajacent to the lumbosacral junction. Due to the weight-bearing properties of the lumbar spine, it is more susceptible to degenerative process in advanced age. The degenerative process normally starts from the intervertebral discs leading to pathologic changes in the ligaments, vertebral bodies, and posterior bulging of posterior disc surface, narrowing of the central spinal canal, osteophyte development and sliding of vertebral bodies (2). The degeneration process leads to the sequential phases of reversible dysfunction, instability characterized by a mild disc height reduction, ligament and joint capsule laxity, and facet joint degeneration and the stabilization phase with reduction in spine range of motion (3). Patients with lumbar spinal stenosis (LSS) typically present with low back pain (LBP), cramping, cauda equine syndrome, and signs of nerve root compression associated by weakness, numbness and tingling in their legs that are worsened with standing and walking (4). This degenerative condition severely restricts function, walking ability, and quality of life (QOL).

When patients become refractory to conservative management, surgical treatment is commonly considered (5). Neurogenic claudication is a clinical syndrome due to LSS, or inflammation of the nerves emanating from the spinal cord (6). Improvement in radiating pain, neurogenic claudication, functional status, and QOL are common goals of surgical treatment for LSS (7). As the use of surgery to treat LSS has increased during the past decades, so has the complexity of the surgical procedures (8). Co-morbidities and higher complication rates of LSS in the elderly patients make it difficult for surgeons to select an appropriate surgical approach for LSS (9). Laminectomies alone are the most common surgical treatment for stenosis. Decompression of the neural structures by means of laminectomy has increasingly been supplemented with lumbar fusion (7), with the intention of minimizing a potential risk of future instability and deformity $(10,11)$. Bae et al (12) conducted a nationwide study on the trends in the surgical management of LSS, and found that the percentage of patients with degenerative lumbar stenosis without spondylolisthesis who underwent fusion increased from $13.5 \%$ to $21.4 \%$ in the span of 5 years. There are several different options for the treatment of a lumbar degenerative disease or lumbar instability among which posterior decompression with posterolateral fusion (PLF) and posterior decompression with posterior lumbar interbody fusion (PLIF) are of widely accepted approaches by most spine surgeons $(10,13-$ 16). Each of these techniques has different clinical outcomes, functional improvements, and neurological complications. Some studies have compared the use of PLF and PLIF for the treatment of spondylolisthesis $(14,15)$. However, inconsistent outcomes of studies have made it difficult to reach consensus on the most useful fusion method which is an optimal surgical approach for the treatment of LSS and degenerative instability. This randomized prospective study aims to compare the clinical and radiological outcomes of PLF and PLIF in the adult patients with LSS and degenerative instability. To our knowledge, this is the first study in the literature which has compared these 2 surgical approaches after lumbar decompression surgery for LSS and degenerative lumbar spine instability in the adult population.

\section{Methods}

\section{Study Design and Population}

We performed a randomized prospective controlled clinical study, in which 88 patients out of a total of 100 patients, 22 men and 66 women aged 50-85 years with LSS and degenerative instability were eligible to participate, and were enrolled from October 2009 to March 2011 to undergo posterior decompression and instrumented fusion by a surgical team in Chamran Hospital, affiliated to Shiraz University of Medical Sciences. A 2-year follow-up was planned from March 2011 to March 2013. A general practitioner not only assessed 100 patients for eligibility, but also evaluated baseline characteristics of eligible patients before randomization. Eligible patients were randomly assigned to two groups by opening sealed envelopes. The envelopes were prepared beforehand and sorted randomly by using random allocation software (computerized random number generators). Randomization was performed by a neurosurgery resident attending the Shahid Motahari Outpatient Clinic, affiliated to Shiraz University of Medical Sciences, after inclusion of the patients into the study by the surgeon. The patient drew one of the 2 envelopes indicating surgical treatment with either PLF or PLIF. Forty-four patients were operated on with PLF with posterior instrumentation 
(Group I) and 44 were operated on with PLIF with posterior instrumentation (Group II). The surgeon was aware of the procedure and all patients were followed by 2 radiologists who were unaware of the study. A rater, who was likewise unaware of the study, verified the results. The radiologists and the rater were not involved in the care of the patients. The Medical Research Ethics Committee as well as Institutional Review Board of Shiraz University of Medical Sciences approved the study protocol before data collection began (approval number: 91-01-01-4438), and written informed consent was obtained from all the patients before the operation. The groups were comparable in the level of preoperative pain and disability. We recorded the demographic information, clinical examination and surgical intervention in all the patients (Table 1). Body mass index (BMI) in the patients were classified as normal weight (18.5-24.99), overweight (25-29.99), and obese ( $\geq 30$ ). LSS was diagnosed according to symptoms and signs of the disease including LBP, leg pain, numbness, and motor weakness, which alleviated with the flexed position and exacerbated in extended position. The diagnosis was confirmed in all the patients with preoperative magnetic resonance imaging (MRI).

\section{Patients and Evaluation}

During the period from October 2009 to March 2011, 100 patients were selected for participation, and 88 patients with LSS and degenerative lumbar spine instability, 22 men (25\%) and 66 women (75\%), were randomized. We excluded 12 patients in accordance with the exclusion criteria. Of the 88 remaining patients, 44 were assigned to undergo PLF with posterior instrumentation and 44 to be operated on with PLIF with posterior instrumentation. The population consisted of 10 men and 34 women in Group I, and 12 men and 32 women in Group II. Mean ages for Groups I and II were 57.76 \pm 8.82 year and $58.35 \pm 9.03$ year, respectively. Mean weight was $75.26 \pm 9.35 \mathrm{~kg}$ in Group I and $76.12 \pm 9.91$ $\mathrm{kg}$ in Group II. Neurogenic claudication was one of the symptoms related to this disease in our patients.

\section{Inclusion Criteria}

The inclusion criteria were: (1) patients older than 50 years; (2) patients with degenerative lumbar stenosis, defined by a Cobb angle less than $10^{\circ}$ on the posteroanterior full-length stand film before surgery and a spinal canal diameter of less than $10 \mathrm{~mm}$; (3) central spinal canal or lateral recess stenosis confirmed by MRI; (4) patients who need surgical intervention such as those with progressive neurologic deficits and bladder dysfunction; (5) no history of previous spinal surgery; (6) symptomatology at least for 6 months; (7) neuroimaging signs of degenerative stenosis; and (8) those who had mechanical LBP and symptoms of neurogenic claudication refractory to conservative management, including rest, pain medicine and physical therapy, for at least 6 months.

\section{Exclusion Criteria}

The exclusion criteria were: (1) patients with mental disorders such as dementia and psychiatric disorders; (2) history of spine surgery or infection; (3) lumbar spine trauma, (4) spinal tumors, (5) scoliosis, (6) Isthmic spondylolysis with or without spondylolisthesis, (7) severe osteoarthritis in the lower limbs, (8) patients with lumbar instability with congenital, traumatic or other etiologies; (9) patients with sagittal imbalance; (10) previous history of severe allergy to tranexamic acid (TXA) during surgery; and (11) missed follow-up visit.

\section{Radiological Evaluation}

The patients' complete neurological examinations were performed and their personal data, including age, gender, height, weight, symptoms, BMI, coexisting disease such as diabetes mellitus (DM), hypertension (HTN), physical examination and history, and radiological findings were gathered. Preoperative standing radiological evaluation included static and bending lumbar spine plain x-rays from T10 to S1 and the hip joints. Computerized tomography (CT) scans and MRI scans of the thoracolumbosacral area without gadolinium injection were used to evaluate the features of degenerative changes such as osteophyte formation, canal, and foraminal stenosis, modic changes, facet joint hypertrophy, degenerative changes in the intervertebral discs of the lumbar spine and their sequelae, and the Cobb angle.

Preoperatively and at 3, 6, 12, and 24 months after the surgery, all patients were classified into 4 groups according to vertebral endplate changes as follows: modic type 0 (without modic changes), modic type 1, modic type 2, and modic type 3 (17). Dual energy x-ray absorptiometry (DEXA) scan was used to diagnose osteoporosis. The Cobb angle, that is the angle between the 2 most tilted vertebrae within a scoliotic curve, was used to measure the degree of scoliosis in each patient (18). The sagittal balance and spinopelvic parameters, including pelvic incidence, pelvic tilt, lumbar lordosis, 
Pain Physician: July/August 2018: 21:383-406

Table 1. Patients' demographic values and distribution of preoperative clinical manifestations in Groups I and II.

\begin{tabular}{|c|c|c|c|}
\hline Parameters & Group I $(n=44)$ & Group II $(n=44)$ & P-value \\
\hline \multicolumn{3}{|l|}{ Gender } & NS \\
\hline Men (\%) & $10(22.7 \%)$ & $12(27.3 \%)$ & \\
\hline Women (\%) & $34(77.3 \%)$ & $32(72.7 \%)$ & \\
\hline Age (years) & $57.76 \pm 8.82$ & $58.35 \pm 9.03$ & NS \\
\hline Weight $(\mathrm{kg})$ & $75.26 \pm 9.35$ & $76.12 \pm 9.91$ & NS \\
\hline $\operatorname{BMI}\left(\mathrm{kg} / \mathrm{m}^{2}\right)$ & $28.8 \pm 4.2$ & $29.3 \pm 4.4$ & NS \\
\hline Normal weight (18.5-24.99) & $8(18.2 \%)$ & $7(16 \%)$ & \\
\hline Overweight (25-29.99) & $34(77.3 \%)$ & $35(79.5 \%)$ & \\
\hline Obese $(\geq 30)$ & $2(4.5 \%)$ & $2(4.5 \%)$ & \\
\hline \multicolumn{3}{|l|}{ BMD } & NS \\
\hline Normal & $17(38.6 \%)$ & $17(38.6 \%)$ & \\
\hline Osteopenia & $10(22.8 \%)$ & $12(27.3 \%)$ & \\
\hline Osteoporotic & $17(38.6 \%)$ & $15(34.1 \%)$ & \\
\hline No. of operated stenosis levels & $2-7$ & $2-7$ & NS \\
\hline Neurologic Deficit & $6(13.6 \%)$ & $8(18.1 \%)$ & NS \\
\hline \multicolumn{3}{|l|}{ Symptoms } & NS \\
\hline Neurologic claudication & $41(93.2 \%)$ & $43(97.7 \%)$ & \\
\hline LBP (VAS) & $25(56.8 \%)$ & $28(63.6 \%)$ & \\
\hline Radicular Pain & $8(18.2 \%)$ & $12(27.3 \%)$ & \\
\hline \multicolumn{3}{|l|}{ Signs } & NS \\
\hline Paresthesia & $33(75 \%)$ & $35(79.5 \%)$ & \\
\hline Weakness & $7(16 \%)$ & $7(16 \%)$ & \\
\hline No sign & $4(9 \%)$ & $2(4.5 \%)$ & \\
\hline \multicolumn{3}{|l|}{ DTR } & NS \\
\hline Normal & $41(93.2 \%)$ & $40(90.9 \%)$ & \\
\hline Hyporeflexia & $2(4.5 \%)$ & $3(6.8 \%)$ & \\
\hline Hyperreflexia & $1(2.3 \%)$ & $1(2.3 \%)$ & \\
\hline \multicolumn{3}{|l|}{ Osteophyte formation } & NS \\
\hline T12 & $1(2.3 \%)$ & $1(2.3 \%)$ & \\
\hline L1 & $5(11.4 \%)$ & $6(13.6 \%)$ & \\
\hline $\mathrm{L} 2$ & $24(54.5 \%)$ & $21(47.7 \%)$ & \\
\hline L3 & $32(72.7 \%)$ & $32(72.7 \%)$ & \\
\hline L4 & $33(75 \%)$ & $30(68.2 \%)$ & \\
\hline L5 & $14(31.8 \%)$ & $17(38.6 \%)$ & \\
\hline S1 & $2(4.5 \%)$ & $2(4.5 \%)$ & \\
\hline \multicolumn{3}{|l|}{ Canal stenosis } & NS \\
\hline L2-L3 & $39(88.6 \%)$ & $40(90.9 \%)$ & \\
\hline L3-L4 & $44(100 \%)$ & $44(100 \%)$ & \\
\hline L4-L5 & $40(90.9 \%)$ & $42(95.5 \%)$ & \\
\hline L5-S1 & $2(4.5 \%)$ & $5(11.4 \%)$ & \\
\hline \multicolumn{3}{|l|}{ Foraminal stenosis } & NS \\
\hline L2-L3 & $9(20.5 \%)$ & $8(18.2 \%)$ & \\
\hline L3-L4 & $27(61.4 \%)$ & $27(61.4 \%)$ & \\
\hline L4-L5 & $36(81.8 \%)$ & $39(88.6 \%)$ & \\
\hline L5-S1 & $4(9.1 \%)$ & $7(15.9 \%)$ & \\
\hline
\end{tabular}


Clinical and Radiological Outcomes of PLF vs. PLIF

Table 1 (cont.). Patients' demographic values and distribution of preoperative clinical manifestations in Groups I and II.

\begin{tabular}{|c|c|c|c|}
\hline Parameters & Group I $(n=44)$ & Group II $(n=44)$ & P-value \\
\hline \multicolumn{3}{|l|}{ Facet joint hypertrophy } & NS \\
\hline L1-L2 & $3(6.8 \%)$ & $3(6.8 \%)$ & \\
\hline L2-L3 & $14(31.8 \%)$ & $10(22.7 \%)$ & \\
\hline L3-L4 & $32(72.7 \%)$ & $34(77.3 \%)$ & \\
\hline L4-L5 & $37(84.1 \%)$ & $37(84.1 \%)$ & \\
\hline L5-S1 & $4(9.1 \%)$ & $5(11.4 \%)$ & \\
\hline \multicolumn{3}{|l|}{ Disc degeneration } & NS \\
\hline L2-L3 & $15(34.1 \%)$ & $17(38.6 \%)$ & \\
\hline L3-L4 & $26(59.1 \%)$ & $28(63.6 \%)$ & \\
\hline L4-L5 & $31(70.5 \%)$ & $34(77.3 \%)$ & \\
\hline L5-S1 & $19(43.2 \%)$ & $19(43.2 \%)$ & \\
\hline \multicolumn{3}{|l|}{ Lumbar curve } & NS \\
\hline Convex to the right side & $37(84.1 \%)$ & $34(77.3 \%)$ & \\
\hline Convex to the left side & $7(15.9 \%)$ & $10(22.7 \%)$ & \\
\hline \multicolumn{3}{|c|}{ Apical vertebra of scoliotic curve } & NS \\
\hline $\mathrm{L} 2$ & $15(34.1 \%)$ & $11(25 \%)$ & \\
\hline L3 & $24(54.5 \%)$ & $27(61.4 \%)$ & \\
\hline L4 & $8(18.2 \%)$ & $6(13.6 \%)$ & \\
\hline Osteoporosis (Using DEXA) & $16(36.4 \%)$ & $13(29.5 \%)$ & NS \\
\hline Sacralization & $1(2.3 \%)$ & $1(2.3 \%)$ & NS \\
\hline Lumbarization & $2(4.5 \%)$ & $3(6.8 \%)$ & NS \\
\hline Spondylolisthesis & $20(45.5 \%)$ & $21(47.7 \%)$ & NS \\
\hline L5-S1 & $2(4.5 \%)$ & $2(4.5 \%)$ & \\
\hline L3-L4 & $9(20.5 \%)$ & $7(15.9 \%)$ & \\
\hline L4-L5 & $9(20.5 \%)$ & $12(27.3 \%)$ & \\
\hline \multicolumn{3}{|l|}{ Instrumented fusion } & NS \\
\hline T12 & $8(18.2 \%)$ & $8(18.2 \%)$ & \\
\hline L1 & $16(36.4 \%)$ & $17(38.6 \%)$ & \\
\hline L2 & $30(68.2 \%)$ & $32(72.7 \%)$ & \\
\hline L3 & $44(100 \%)$ & $44(100 \%)$ & \\
\hline L4 & $43(97.7 \%)$ & $42(95.5 \%)$ & \\
\hline L5 & $39(88.6 \%)$ & $38(86.4 \%)$ & \\
\hline S1 & $17(38.6 \%)$ & $17(38.6 \%)$ & \\
\hline
\end{tabular}

NS indicates not significant; BMI, bone mass index; BMD, bone mineral density; LBP, low back pain; VAS, visual analog scale; DTR, deep tendon reflex; Values are expressed as frequency and percent unless stated as mean \pm SD.

and sacral slope, were measured carefully before and 3 months after the surgery at the Shahid Motahari Outpatient Clinic, affiliated to Shiraz University of Medical Sciences (Fig. 1). We drew the sagittal plumb line and measured the distance between this line and posterior superior corner of S1 vertebra. According to Jackson and McManus (19), if the vertical plumb line lied anterior to posterior superior corner of S1, sagittal vertical axis (SVA) was identified as positive number and if it lied posterior to the corner, it was identified as negative number. In other words, the plumb line that passed anterior to the $\mathrm{S} 1$ was considered as positive sagittal balance $(>+4)$ and a line that passed posterior to it was considered as negative sagittal balance $(<-4)$. Pelvic incidence was defined as the angle between the line perpendicular to the sacral plate at the midpoint and the line connecting this point to the femoral heads axis. The pelvic incidence is the main parameter which 
is fixed and does not change with posture or positioning and is based on the morphology of the pelvic. Pelvic tilt was defined as the angle between the vertical and the line through the midpoint of the sacral plate to femoral heads axis. Sacral slope was defined as the angle between the horizontal plane and the sacral plate. Lumbar lordosis was measured accord-

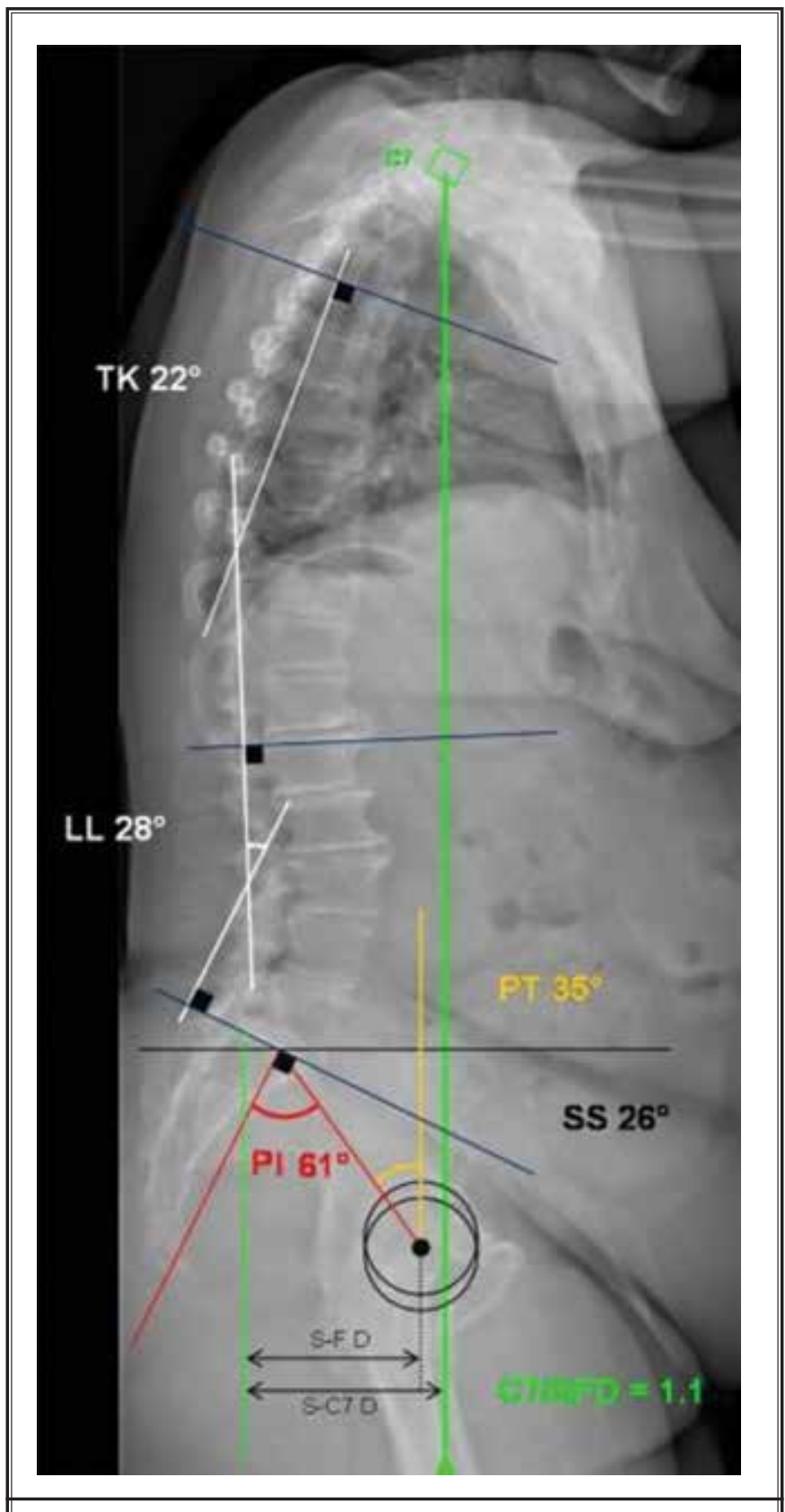

Fig. 1. Measurement of SVA and spinopelvic parameters. ing to Cobb's method (20) from the superior border of $\mathrm{L} 1$ to the superior border of $\mathrm{S} 1$ and was presented as the angle. All radiographs of the patients were reviewed by an independent radiologist. Studies of different populations in the literature have reported that the normal range of the pelvic incidence is between 40 to $65^{\circ}$, the normal range of sacral slope is between 30 to $50^{\circ}$, the normal range of pelvic tilt is between 5 to $30^{\circ}$, and the normal range of lumbar lordosis is between 31 and 70 (21).

\section{Operative Technique}

On the day of the operation, cefazolin $1 \mathrm{~g}$ and gentamicin $80 \mathrm{mg}$ were administered by intravenous infusion within 1 hour prior to incision. General anesthesia was induced in all patients with thiopental $(5-7 \mathrm{mg} / \mathrm{kg})$ and fentanyl (1-1.5 microgm $/ \mathrm{kg}$ ). A prophylactic low dose of TXA 10 $\mathrm{mg} / \mathrm{kg}$ (Caspian Tamin Pharmaceutical Co., Rasht, Iran) was administered to all of the patients at the initiation of induction of anesthesia over 10 minutes followed by a maintenance dose of 1 $\mathrm{mg} / \mathrm{kg} / \mathrm{h}$ by a syringe infusion pump to reduce blood transfusion requirements during surgery (22). Atracurium $(0.6 \mathrm{mg} / \mathrm{kg})$ was administrated to facilitate endotracheal intubation. Anesthesia was maintained with a propofol infusion 100-200 $\mathrm{mg} / \mathrm{kg} / \mathrm{min}$ and $70 \%$ nitrous oxide in oxygen and intermittent vecuronium when indicated. X-ray localization was used to plan the skin incision, which was infiltrated with $10 \mathrm{~mL}$ of $1 \%$ Lidocaine. All surgeries were performed by one spine surgeon. The patients were carefully placed prone, a skin incision was made in the midline and paravertebral muscle dissection was performed. Spinous processes, laminae, the bilateral facets, and transverse processes were exposed. Posterior decompression, consisting of the removal of the spinous process, bilateral laminectomy, partial bilateral facetectomy, and foraminotomy, was performed for the levels with canal and foraminal stenosis. Fluoroscopically-guided transpedicular fixation was performed at the involved level and its caudal vertebra as a standard technique. After performing neural decompression, the osseous surfaces of the transverse processes and facets were decorticated using a high-speed drill to expose cancellous bone and facet joints and also to make appropriate bed for applying bone graft to achieve good 
fusion $(10,20,23)$. Possible complications of surgery such as nerve root injury, dural tears, and superficial infection were evaluated at each follow-up visit.

\section{Instrumented Fusion}

The instrumented fusion consisted of the placement of pedicle screw instrumentation at the decompressed level or levels followed by the placement of a connecting $\operatorname{rod}(10,20,23)$. The fusion was extended to the sacrum if there were significant degenerative change or instability at L5-S1 level. Fusion $\leq 3$ levels was regarded as short segment fusion and fusion $\geq 4$ levels was regarded as long segment fusion. Implants International Ltd. (Teesside industrial estate, Thornby, United Kingdom) was used for posterior pedicular fixation. We used autologous bone graft from the excised loose lamina and spinous process mixed with synthetic bone substitute granules (Medical Biomat Inc., Warsaw, Indiana) to achieve intertransverse fusion. C-arm fluoroscopy was used to evaluate the accuracy of pedicle screw fixation. Fusion rate was qualitatively measured by $\mathrm{x}$-ray and CT scans after $3,6,12$, and 24 months. Fusion was classified as bony fusion (good fusion), segmental bony fusion (fair fusion), and lack of bony fusion or subluxation in dynamic post-operative radiographies (bad fusion) $(10,20,23)$. Successful fusion was defined as the integrated bony fusion at the fusion bed without motion in a dynamic graph $(10,20,23)$. Negative pressure drainage was placed before the surgical incision was closed.

\section{Blood Loss Measurement}

Intraoperative blood loss was measured by weighing lap sponges and surgical gauzes from the operative field with a digital scale, suction drainage, and an estimate of loss on the surgical drapes and gowns. Postoperative blood loss was the amount of blood recovered in the surgical drains if intraoperative drains were placed. As x-ray detectable gauzes are at different weights (4 or $6 \mathrm{~g}$ ), the eye measurement of the amount of blood in each gauze is imprecise, and blood density is $1.006 \mathrm{~g} / \mathrm{cm} 3$; furthermore, during the surgery, we maintained all bloody $x$-ray detectable gauzes in a device called Beex container to prevent evaporation of the fluids from the gauze. Then, each piece of gauze was weighed and the total blood loss was determined based on milliliters.

\section{Postoperative Treatment}

The patients were transferred to the post anesthesia care unit and they were assessed neurologically.
During the first 24 hours post-operatively, the patients received a single $4 \mathrm{mg}$ intravenous dose of morphine without using any continuous infusion on a pro re nata (PRN) basis when they had severe pain, measured according to Huskisson visual analog scale (VAS) (24) with scores ranging from 1 (no pain) to 10 (excruciating pain). According to this scale, VAS score more than 6 was considered as severe pain (25-28). They took 3-day routine rest in bed and then started to ambulate supported by lumbar brace for 6 weeks after the operation. Waist and back functional training was gradually added. For pain management at the first month after surgery, we prescribed acetaminophen $500 \mathrm{mg}$ compound tablets with codeine twice a day PRN for patients with severe pain in outpatient settings and the patients were allowed to continue this protocol if they had persistent pain. The use of nonsteroidal anti-inflammatory drugs (NSAIDs)was prevented because of their negative effects on fusion (29). The patients were evaluated at the $3,6,12$ and 24 month follow-up visits.

\section{Outcome Measures}

Primary outcomes were the control of LBP with or without radicular pain, which was evaluated preoperatively and at 24 hours and 3, 6, 12, and 24 months after surgery, and the improvement of QOL or functional daily activity which was assessed preoperatively and at $3,6,12$, and 24 months postoperatively in the Shahid Motahari Outpatient Clinic. Severity of postoperative LBP and radicular pain during the follow-up period was evaluated using the VAS (24). The day before surgery, patients were informed how to use the VAS. QOL was evaluated by a questionnaire based on the Oswestry disability index (ODI) version 2, which is a functional disability measurement of QOL comprising 6 items in 10 dimensions: pain intensity, personal care, lifting, walking, sitting, standing, sleeping, social life, traveling, and change in the degree of pain (30). Table 2 describes the correlation between ODI score ranges and severity of disability. Because the ODI was developed for English speaking patients, we used its Persian translation (with permission from the School of Rehabilitation, affiliated with Tehran University of Medical Sciences). The patients completed the Persian translation of the ODI questionnaire for measurement of the severity of disability in the thoracolumbosacral area. The Persian translation of this instrument may have retained some cultural or linguistic biases, but this problem is common to many studies that are conducted in nonnative English speaking settings. All measurements were taken by 2 
Pain Physician: July/August 2018: 21:383-406

Table 2. Correlation between severity of disability and ODI score ranges.

\begin{tabular}{||c|l||}
\hline $\begin{array}{c}\text { Degree of Severity of } \\
\text { Disability }\end{array}$ & \multicolumn{1}{c||}{ Interpretation } \\
\hline Minimal disability: 0-20\% & $\begin{array}{l}\text { The patient can cope with most living activities. Usually no treatment is indicated apart from advice on lifting } \\
\text { sitting and exercise. }\end{array}$ \\
\hline $\begin{array}{c}\text { Moderate disability: } \\
21-40 \%\end{array}$ & $\begin{array}{l}\text { The patient experiences more pain and difficulty with sitting, lifting and standing. Travel and social life are more } \\
\text { difficult and they may be disabled from work. Personal care, sexual activity and sleeping are not grossly affected } \\
\text { and the patient can usually be managed by conservative means. }\end{array}$ \\
\hline Severe disability: 41-60\% & $\begin{array}{l}\text { Pain remains the main problem in this group but activities of daily living are affected. These patients require a } \\
\text { detailed investigation. }\end{array}$ \\
\hline Crippled: $61-80 \%$ & Back pain impinges on all aspects of the patient's life. Positive intervention is required. \\
\hline $81-100 \%$ & These patients are either bed-bound or exaggerating their symptoms. \\
\hline \hline
\end{tabular}

independent spine surgeons. Because the inflammation of the surgical site reduces at 2 months after the surgery and also severe LBP due to surgical manipulation decreases gradually at postoperative 3 months (31) we selected a follow-up period of 24 months for VAS and ODI to better evaluate the patients' clinical outcomes.

\section{Statistical Analysis}

Excel 2007 and Statistical Package for Social Sciences (SPSS Inc., Chicago, IL, USA) version 16.0 was used for data analysis. Frequency, mean and SD, and frequency percentage were used for descriptive statistics of clinical and radiographic changes. NCSS 11, LLC. (Kaysville, Utah) was used for sample size and power analysis calculations. Accordingly, the total sample size was determined as 44 patients in the PLF group and 44 patients in the PLIF group, assuming $\alpha=0.05, \beta=0.2, d$ $=\mu_{1}-\mu_{2}=2.3-1.7=0.6$, and $s_{1}=s_{2}=0.75$. Proportions were compared using Chi-square test. The parametric variables with normal distribution were compared between groups using independent t-test. Statistical analysis was conducted using the paired student's t-test to compare continuous intragroup data (percentage of subluxation, foraminal area, disc height, and slippage angle) before and after surgery, and the unpaired t-test was used to compare intergroup data. Power calculation revealed a power of $85 \%$ to detect at least $5 \%$ difference between sagittal balance, pelvic incidence, lumbar lordosis, and sacral slope. Fisher's exact test was used to evaluate fusion rate, and the Mann-Whitney $\mathrm{U}$ test was used to compare categorical data (VAS and ODI). The analysis of variance (ANOVA) with repeated measurements was used to compare the mean VAS at five time points of 24 hours, 3, 6, 12, and 24 months postoperatively and the mean ODI scores at 3, 6, 12, and 24 months postoperatively to show the trend of changes of VAS and ODI over time in the 2 groups. $\mathrm{P}<$ 0.05 was considered statistically significant.

\section{Results}

From October 2009 to March 2011, 88 patients, aged 50 to 85 years, were selected for enrollment. Table 1 represents all patients' demographic values and distribution of clinical manifestations preoperatively. Mean intraoperative blood loss was $767.87 \pm 450 \mathrm{~mL}$ in Group I and $883.05 \pm 390.24 \mathrm{~mL}$ in Group II. Mean surgical duration was $230 \pm 66.9 \mathrm{~min}$ in Group I and 325 $\pm 63.6 \mathrm{~min}$ in Group II. None of the patients had abnormal lumbar lordosis. The most neurological symptom in our patients was neurogenic claudication (Table 1). At 3 months after the surgery, 4 patients $(9.1 \%)$ in Group I and 7 patients (15.9\%) in Group II had complaints of mild neurogenic claudication that did not need any new intervention. At 12 months after the surgery, only one patient $(2.3 \%)$ in Group II had mild neurogenic claudication.

Table 3 shows the distribution and prevalence of modic changes at different levels preoperatively and at 3,6, 12 and 24 months postoperatively. Before the operation in Group I, 28 patients (63.6\%) had several modic lesions at multi-levels, 10 patients $(22.7 \%)$ showed a single modic lesion, and 6 patients (13.6\%) had no modic lesion. In Group II, 30 patients (68.2\%) had several modic lesions at multi-levels, 7 patients (15.9\%) showed a single modic lesion, and 7 patients $(15.9 \%)$ had no modic lesion before the surgery. Preoperatively and at 3, 6, 12, and 24 months after the surgery, the most modic changes in decreasing order in the 2 groups were present at the L4-L5, L5-S1, and L3-L4 (Table 3). Before and after the surgery, modic Type 2 lesions were more common in the patients. In Group I, of the 39 Type 1 lesions, 7 (15.9\%) converted to Type 2, $3(6.8 \%)$ converted to normal (Type 0), and 29 $(65.9 \%)$ remained Type 1 at 3 months after the surgery. Of the remaining 29 Type 1 lesions, $3(6.8 \%)$ converted to Type 2 and 2 (4.5\%) converted to normal at 6 months 
Clinical and Radiological Outcomes of PLF vs. PLIF

Table 3. Distribution and prevalence of modic changes at different levels in Groups I and II.

\begin{tabular}{|c|c|c|c|c|c|}
\hline & $\begin{array}{c}\text { Type 0 } \\
\text { (No modic Change) } \\
\text { n }(\%)\end{array}$ & $\begin{array}{l}\text { Type } 1 \\
\text { n (\%) }\end{array}$ & $\begin{array}{l}\text { Type } 2 \\
\text { n (\%) }\end{array}$ & $\begin{array}{l}\text { Type } 3 \\
\text { n (\%) }\end{array}$ & $\begin{array}{c}\text { Total of Types 1-3 } \\
\text { n (\%) }\end{array}$ \\
\hline \multicolumn{6}{|l|}{ Group 1} \\
\hline \multicolumn{6}{|l|}{ Preop } \\
\hline T12 - L1 & $44(100 \%)$ & 0 & 0 & 0 & 0 \\
\hline $\mathrm{L} 1-\mathrm{L} 2$ & $38(86.4 \%)$ & $3(6.8 \%)$ & $2(4.5 \%)$ & $1(2.3 \%)$ & $6(13.6 \%)$ \\
\hline $\mathrm{L} 2-\mathrm{L} 3$ & $33(75 \%)$ & $5(11.4 \%)$ & $4(9.1 \%)$ & $2(4.5 \%)$ & $11(25 \%)$ \\
\hline L3 - L4 & $28(63.6 \%)$ & $7(15.9 \%)$ & $7(15.9 \%)$ & $2(4.5 \%)$ & $16(36.4 \%)$ \\
\hline L4 - L5 & $8(18.2 \%)$ & $14(31.8 \%)$ & $18(40.9 \%)$ & $4(9.1 \%)$ & $36(81.8 \%)$ \\
\hline $\mathrm{L} 5-\mathrm{S} 1$ & $20(45.5 \%)$ & $10(22.7 \%)$ & $11(25 \%)$ & $3(6.8 \%)$ & $24(54.5 \%)$ \\
\hline Total & 171 & 39 & 42 & 12 & 93 \\
\hline \multicolumn{6}{|c|}{3 months postop } \\
\hline $\mathrm{T} 12-\mathrm{L} 1$ & $44(100 \%)$ & 0 & 0 & 0 & 0 \\
\hline $\mathrm{L} 1-\mathrm{L} 2$ & $38(86.4 \%)$ & $2(4.5 \%)$ & $3(6.8 \%)$ & $1(2.3 \%)$ & $6(13.5 \%)$ \\
\hline L2 - L3 & $33(75 \%)$ & $3(6.8 \%)$ & $6(13.6 \%)$ & $2(4.5 \%)$ & $11(25 \%)$ \\
\hline $\mathrm{L} 3-\mathrm{L} 4$ & $30(68.2 \%)$ & $6(13.6 \%)$ & $6(13.6 \%)$ & $2(4.5 \%)$ & $14(31.8 \%)$ \\
\hline L4 - L5 & $13(29.5 \%)$ & $10(22.7 \%)$ & $17(38.6 \%)$ & $4(9.1 \%)$ & $31(70.5 \%)$ \\
\hline $\mathrm{L} 5-\mathrm{S} 1$ & $22(50 \%)$ & $8(18.2 \%)$ & $11(25 \%)$ & $3(6.8 \%)$ & $22(50 \%)$ \\
\hline Total & 180 & 29 & 43 & 12 & 84 \\
\hline \multicolumn{6}{|c|}{6 months postop } \\
\hline T12 - L1 & $44(100 \%)$ & 0 & 0 & 0 & 0 \\
\hline $\mathrm{L} 1-\mathrm{L} 2$ & $38(86.4 \%)$ & $2(4.5 \%)$ & $3(6.8 \%)$ & $1(2.3 \%)$ & $6(13.5 \%)$ \\
\hline $\mathrm{L} 2$ - L3 & $34(77.3 \%)$ & $3(6.8 \%)$ & $5(11.4 \%)$ & $2(4.5 \%)$ & $10(22.7 \%)$ \\
\hline L3 - L4 & $33(75 \%)$ & $4(9.1 \%)$ & $5(11.4 \%)$ & $2(4.5 \%)$ & $11(25 \%)$ \\
\hline L4 - L5 & $16(36.4 \%)$ & $9(20.5 \%)$ & $15(34.1 \%)$ & $4(9.1 \%)$ & $28(63.6 \%)$ \\
\hline L5 - S1 & $23(52.3 \%)$ & $6(13.6 \%)$ & $12(27.3 \%)$ & $3(6.8 \%)$ & $21(47.7 \%)$ \\
\hline Total & 188 & 24 & 40 & 12 & 76 \\
\hline \multicolumn{6}{|c|}{12 months postop } \\
\hline T12 - L1 & $44(100 \%)$ & 0 & 0 & 0 & 0 \\
\hline $\mathrm{L} 1-\mathrm{L} 2$ & $41(93.2 \%)$ & 0 & $2(4.5 \%)$ & $1(2.3 \%)$ & $3(6.8 \%)$ \\
\hline $\mathrm{L} 2-\mathrm{L} 3$ & $39(88.6 \%)$ & $1(2.3 \%)$ & $2(4.5 \%)$ & $2(4.5 \%)$ & $5(11.4 \%)$ \\
\hline L3 - L4 & $38(86.4 \%)$ & $1(2.3 \%)$ & $3(6.8 \%)$ & $2(4.5 \%)$ & $6(13.5 \%)$ \\
\hline L4 - L5 & $27(61.4 \%)$ & $4(9.1 \%)$ & $9(20.5 \%)$ & $4(9.1 \%)$ & $17(38.6 \%)$ \\
\hline $\mathrm{L} 5-\mathrm{S} 1$ & $32(72.7 \%)$ & $3(6.8 \%)$ & $6(13.5 \%)$ & $3(6.8 \%)$ & $12(27.3 \%)$ \\
\hline Total & 221 & 9 & 22 & 12 & 43 \\
\hline \multicolumn{6}{|c|}{24 months postop } \\
\hline $\mathrm{T} 12-\mathrm{L} 1$ & $44(100 \%)$ & 0 & 0 & 0 & 0 \\
\hline $\mathrm{L} 1-\mathrm{L} 2$ & $42(95.5 \%)$ & 0 & $1(2.3 \%)$ & $1(2.3 \%)$ & $2(4.5 \%)$ \\
\hline $\mathrm{L} 2-\mathrm{L} 3$ & $40(90.9 \%)$ & $1(2.3 \%)$ & $1(2.3 \%)$ & $2(4.5 \%)$ & $4(9.1 \%)$ \\
\hline L3 - L4 & $40(90.9 \%)$ & 0 & $2(4.5 \%)$ & $2(4.5 \%)$ & $4(9.1 \%)$ \\
\hline L4 - L5 & $34(77.3 \%)$ & $2(4.5 \%)$ & $4(9.1 \%)$ & $4(9.1 \%)$ & $10(22.7 \%)$ \\
\hline L5 - S1 & $37(84.1 \%)$ & $1(2.3 \%)$ & $3(6.8 \%)$ & $3(6.8 \%)$ & $7(15.9 \%)$ \\
\hline Total & 237 & 4 & 11 & 12 & 27 \\
\hline
\end{tabular}


Pain Physician: July/August 2018: 21:383-406

Table 3 (cont.). Distribution and prevalence of modic changes at different levels in Groups I and II.

\begin{tabular}{|c|c|c|c|c|c|}
\hline & $\begin{array}{c}\text { Type 0 } \\
\text { (No modic Change) } \\
\text { n (\%) }\end{array}$ & $\begin{array}{l}\text { Type } 1 \\
\text { n (\%) }\end{array}$ & $\begin{array}{l}\text { Type } 2 \\
\text { n (\%) }\end{array}$ & $\begin{array}{l}\text { Type } 3 \\
\text { n (\%) }\end{array}$ & $\begin{array}{c}\text { Total of Types 1-3 } \\
\text { n (\%) }\end{array}$ \\
\hline \multicolumn{6}{|l|}{ Group II } \\
\hline \multicolumn{6}{|l|}{ Preop } \\
\hline $\mathrm{T} 12$ - L1 & $44(100 \%)$ & 0 & 0 & 0 & 0 \\
\hline $\mathrm{L} 1-\mathrm{L} 2$ & $37(84.1 \%)$ & $2(4.5 \%)$ & $3(6.8 \%)$ & $2(4.5 \%)$ & $7(15.9 \%)$ \\
\hline L2 - L3 & $34(77.3 \%)$ & $5(11.4 \%)$ & $4(9.1 \%)$ & $1(2.3 \%)$ & $10(22.7 \%)$ \\
\hline L3 - L4 & $27(61.4 \%)$ & $6(13.6 \%)$ & $8(18.2 \%)$ & $3(6.8 \%)$ & $17(38.6 \%)$ \\
\hline L4 - L5 & $9(20.5 \%)$ & $13(29.5 \%)$ & $17(38.6 \%)$ & $5(11.4 \%)$ & 35 (79.5\%) \\
\hline L5 - S1 & $20(45.5 \%)$ & $11(25 \%)$ & $9(20.5 \%)$ & $4(9.1 \%)$ & $24(54.5 \%)$ \\
\hline Total & 171 & 37 & 41 & 15 & 93 \\
\hline \multicolumn{6}{|c|}{3 months postop } \\
\hline $\mathrm{T} 12$ - L1 & $44(100 \%)$ & 0 & 0 & 0 & 0 \\
\hline $\mathrm{L} 1-\mathrm{L} 2$ & $37(84.1 \%)$ & $2(4.5 \%)$ & $3(6.8 \%)$ & $2(4.5 \%)$ & $7(15.9 \%)$ \\
\hline $\mathrm{L} 2-\mathrm{L} 3$ & $34(77.3 \%)$ & $4(9.1 \%)$ & $5(11.4 \%)$ & $1(2.3 \%)$ & $10(22.7 \%)$ \\
\hline L3 - L4 & $28(63.6 \%)$ & $5(11.4 \%)$ & $8(18.2 \%)$ & $3(6.8 \%)$ & $16(36.4 \%)$ \\
\hline L4 - L5 & $11(25 \%)$ & $11(25 \%)$ & $17(38.6 \%)$ & $5(11.4 \%)$ & $33(75 \%)$ \\
\hline L5 - S1 & $20(45.5 \%)$ & $9(20.5 \%)$ & $11(25 \%)$ & $4(9.1 \%)$ & $24(54.5 \%)$ \\
\hline Total & 174 & 31 & 44 & 15 & 90 \\
\hline \multicolumn{6}{|c|}{6 months postop } \\
\hline $\mathrm{T} 12-\mathrm{L} 1$ & $44(100 \%)$ & 0 & 0 & 0 & 0 \\
\hline $\mathrm{L} 1-\mathrm{L} 2$ & $37(84.1 \%)$ & $2(4.5 \%)$ & $3(6.8 \%)$ & $2(4.5 \%)$ & $7(15.9 \%)$ \\
\hline $\mathrm{L} 2$ - L3 & $34(77.3 \%)$ & $3(6.8 \%)$ & $6(13.6 \%)$ & $1(2.3 \%)$ & $10(22.7 \%)$ \\
\hline L3 - L4 & $30(68.2 \%)$ & $4(9.1 \%)$ & $7(15.9 \%)$ & $3(6.8 \%)$ & $14(31.8 \%)$ \\
\hline L4 - L5 & $16(36.4 \%)$ & $8(18.2 \%)$ & $15(34.1 \%)$ & $5(11.4 \%)$ & $28(63.6 \%)$ \\
\hline $\mathrm{L} 5-\mathrm{S} 1$ & $24(54.5 \%)$ & $6(13.6 \%)$ & $10(22.7 \%)$ & $4(9.1 \%)$ & $20(45.5 \%)$ \\
\hline Total & 185 & 23 & 41 & 15 & 79 \\
\hline \multicolumn{6}{|c|}{12 months postop } \\
\hline $\mathrm{T} 12$ - L1 & $44(100 \%)$ & 0 & 0 & 0 & 0 \\
\hline $\mathrm{L} 1-\mathrm{L} 2$ & $39(88.6 \%)$ & $1(2.3 \%)$ & $2(4.5 \%)$ & $2(4.5 \%)$ & $5(11.4 \%)$ \\
\hline $\mathrm{L} 2-\mathrm{L} 3$ & $39(88.6 \%)$ & $1(2.3 \%)$ & $3(6.8 \%)$ & $1(2.3 \%)$ & $5(11.4 \%)$ \\
\hline L3 - L4 & $36(81.8 \%)$ & $2(4.5 \%)$ & $3(6.8 \%)$ & $3(6.8 \%)$ & $8(18.2 \%)$ \\
\hline L4 - L5 & $27(61.4 \%)$ & $4(9.1 \%)$ & $8(18.2 \%)$ & $5(11.4 \%)$ & $17(38.6 \%)$ \\
\hline $\mathrm{L} 5-\mathrm{S} 1$ & $34(77.3 \%)$ & $2(4.5 \%)$ & $4(9.1 \%)$ & $4(9.1 \%)$ & $10(22.7 \%)$ \\
\hline Total & 219 & 10 & 20 & 15 & 45 \\
\hline \multicolumn{6}{|c|}{24 months postop } \\
\hline $\mathrm{T} 12-\mathrm{L} 1$ & $44(100 \%)$ & 0 & 0 & 0 & 0 \\
\hline $\mathrm{L} 1-\mathrm{L} 2$ & $41(93.2 \%)$ & 0 & $1(2.3 \%)$ & $2(4.5 \%)$ & $3(6.8 \%)$ \\
\hline $\mathrm{L} 2-\mathrm{L} 3$ & 40 (90.9\%) & $1(2.3 \%)$ & $2(4.5 \%)$ & $1(2.3 \%)$ & $4(9.1 \%)$ \\
\hline $\mathrm{L} 3-\mathrm{L} 4$ & $39(8.6 \%)$ & 0 & $2(4.5 \%)$ & $3(6.8 \%)$ & $5(11.4 \%)$ \\
\hline L4 - L5 & $32(72.7 \%)$ & $2(4.5 \%)$ & $5(11.4 \%)$ & $5(11.4 \%)$ & $12(27.3 \%)$ \\
\hline L5 - S1 & $36(81.8 \%)$ & $1(2.3 \%)$ & $3(6.8 \%)$ & $4(9.1 \%)$ & $8(18.2 \%)$ \\
\hline Total & 232 & 4 & 13 & 15 & 32 \\
\hline
\end{tabular}


after the surgery. At 12 months after the surgery, 8 Type 1 lesions (18.2\%) converted to Type 2 and 7 (15.9\%) converted to normal and finally at 24 months after the surgery in Group I, 3 Type 1 lesions (6.8\%) converted to Type 2, 2 (4.5\%) converted to normal, and $4(9.1 \%)$ remained Type 1 . In Group II, of the 37 Type 1 lesions, $5(11.4 \%)$ converted to Type $2,1(2.3 \%)$ converted to Type 0 , and $31(70.5 \%)$ remained Type 1 at 3 months after the surgery. Of the remaining 31 Type 1 lesions, $5(11.4 \%)$ converted to Type 2 and $3(6.8 \%)$ converted to Type 0 at 6 months after the surgery. At 12 months after the surgery, 8 Type 1 lesions (18.2\%) converted to Type 2 and 5 (11.4\%) converted to Type 0 and finally at 24 months after the surgery in Group II, 5 Type 1 lesions $(11.4 \%)$ converted to Type 2 and $1(2.3 \%)$ converted to Type 0. In Group I, 6 Type 2 lesions (13.6\%) converted to normal at 3 months postoperatively, 6 (13.6\%) converted to normal at 6 months postoperatively, 26 $(59.1 \%)$ converted to normal at 12 months after the surgery, and at the last follow-up, 14 (31.8\%) Type 2 lesions converted to normal. In Group II, 2 Type 2 lesions $(4.5 \%)$ converted to Type 0 at 3 months postoperatively, $8(18.2 \%)$ converted to Type 0 at 6 months postoperatively, $29(65.9 \%)$ converted to Type 0 at 12 months after the surgery, and at the last follow-up, 12 (27.3\%) Type 2 lesions converted to Type 0 . No modic Type 2 lesion converted to Type 1 during the follow-up period. Totally, in Group I, 35 Type 1 lesions converted to either normal or Type 2 and 31 Type 2 lesions converted to normal at the last follow-up in comparison with the modic lesions preoperatively. In Group II, a total of 33 Type 1 lesions converted to either normal or Type 2 and 28 Type 2 lesions converted to normal at the last follow-up in comparison with the modic lesions preoperatively. None of the preexisting Type 3 lesions exhibited reverse conversion to another type during the follow-up period.

Table 1 shows that major complaints of the patients in the 2 groups before the surgery were neurologic claudication, LBP, and radicular pain. The mean VAS, radicular pain, ODI, and Cobb angle scores of the two groups before and at 3, 6, 12 and 24 months after the surgery are shown in Table 4. VAS scores in Group I improved significantly from a mean of $7.87 \pm 1.07$ preoperatively to $4.86 \pm 1.83$ at 24 hours, $4.48 \pm 1.75$ at 3 months, 4.02 \pm 1.49 at 6 months, $3.27 \pm 1.21$ at 12 months and $2.20 \pm$ 1.15 at 24 months postoperatively $(P<.001)$. VAS scores in Group II improved significantly from a mean of 8.01 \pm 1.56 preoperatively to $4.98 \pm 1.84$ at 24 hours, $4.57 \pm$ 1.73 at 3 months, $4.23 \pm 1.51$ at 6 months, $3.85 \pm 1.28$ at
12 months and $2.53 \pm 1.09$ at 24 months postoperatively $(P<0.001)$. However, at the last follow-up, the mean reduction in VAS scores in Group I was more than the mean reduction in VAS scores in Group II (5.67 vs. 5.48, respectively). During the first 24 hours post-operatively, 1 patient $(2.3 \%)$ in Group I and 3 patients $(6.8 \%)$ in Group II had severe LBP who received a single $4 \mathrm{mg}$ intravenous dose of morphine without using any continuous infusion. The mean radicular pain scores decreased significantly during the follow-up period in Group I $(6.73 \pm 2.23$ preoperatively vs. $1.04 \pm 1.02$ at the last follow-up, $P<$ $0.001)$ and in Group II (6.82 \pm 2.31 preoperatively vs. 1.30 \pm 1.06 at the last follow-up, $P<0.001$ ), but the mean reduction in the radicular pain scores in Group I was more than the mean reduction in the radicular pain scores in Group II (5.69 vs. 5.52, respectively). There was no correlation between blood group, job, and underlying diseases in the patients and improvement in radicular pain and LBP in the 2 groups. Table 4 shows that the mean ODI score in Groups I and II at 3, 6, 12, and 24 months after the surgery was significantly lower than the mean preoperative ODI score $(P<0.001)$. At the last follow-up, the patients in Group I had more improvement in the ODI score than the patients in Group II (42.75 vs. 40.94, respectively). The range of preoperative Cobb angles in the patients was 7 to $10^{\circ}$. Change in curve angle after surgery was statistically significant in the 2 groups. The mean Cobb angle in Group I changed significantly from $9.7^{\circ} \pm 3.77$ preoperatively to $3.38^{\circ} \pm 1.65$ at 24 hours, $3.35^{\circ} \pm 3.16$ at 3 months, $3.24^{\circ} \pm 2.12$ at 6 months, $3.19^{\circ}$ \pm 2.09 at 12 months, and $3.06^{\circ} \pm 2.04$ at 24 months postoperatively $(P<0.001)$. The mean Cobb angle in Group II changed significantly from $9.2^{\circ} \pm 3.86$ preoperatively to $3.39^{\circ} \pm 1.66$ at 24 hours, $3.37^{\circ} \pm 3.19$ at 3 months, $3.31^{\circ} \pm 2.13$ at 6 months, $3.26^{\circ} \pm 2.06$ at 12 months, and $3.07^{\circ} \pm 2.01$ at 24 months postoperatively $(P<0.001)$. Table 4 shows that Cobb angle correction was statistically significant during the follow-up periods compared with the preoperative Cobb angle $(P<0.001)$. At the last follow-up, the mean Cobb angle correction in the patients in Group I was more than the patients in Group II (6.64 vs. 6.13, respectively). Moderate disability occurred more frequently in the 2 groups at 3 and 6 months after the surgery while at 12 and 24 months after the surgery, the 2 groups had minimal disability and the difference between the 2 groups were statistically significant $(P<$ 0.001 ). At the last follow-up, the number of the patients with minimal disability in Group I was more than the number of the patients with minimal disability in Group II (42 vs. 39, respectively). 
Pain Physician: July/August 2018: 21:383-406

Table 4. Clinical and radiological outcomes in the patients of the 2 groups.

\begin{tabular}{|c|c|c|c|}
\hline Parameters & Group I $(n=44)$ & Group II $(n=44)$ & $P$-value \\
\hline \multicolumn{3}{|l|}{ LBP, VAS score } & $<0.001$ \\
\hline Preop & $7.87 \pm 1.07$ & $8.01 \pm 1.56$ & \\
\hline $24 \mathrm{~h}$ postop & $4.86 \pm 1.83$ & $4.98 \pm 1.84$ & \\
\hline 3 mos postop & $4.48 \pm 1.75$ & $4.57 \pm 1.73$ & \\
\hline 6 mos postop & $4.02 \pm 1.49$ & $4.23 \pm 1.51$ & \\
\hline 12 mos postop & $3.27 \pm 1.21$ & $3.85 \pm 1.28$ & \\
\hline 24 mos postop & $2.20 \pm 1.15$ & $2.53 \pm 1.09$ & \\
\hline \multicolumn{3}{|l|}{ Radicular pain } & $<0.001$ \\
\hline Preop & $6.73 \pm 2.23$ & $6.82 \pm 2.31$ & \\
\hline $24 \mathrm{~h}$ postop & $3.25 \pm 1.67$ & $3.58 \pm 1.58$ & \\
\hline 3 mos postop & $2.55 \pm 1.16$ & $2.59 \pm 1.22$ & \\
\hline 6 mos postop & $2.05 \pm 1.07$ & $2.23 \pm 1.09$ & \\
\hline 12 mos postop & $2 \pm 1.03$ & $2.15 \pm 1.04$ & \\
\hline 24 mos postop & $1.04 \pm 1.02$ & $1.30 \pm 1.06$ & \\
\hline \multicolumn{3}{|l|}{ ODI } & $<0.001$ \\
\hline Preop & $61.06 \pm 12.28$ & $62.18 \pm 12.25$ & \\
\hline 3 mos postop & $43.36 \pm 13.01$ & $49.81 \pm 16.04$ & \\
\hline 6 mos postop & $34.45 \pm 15.68$ & $37.53 \pm 15.84$ & \\
\hline 12 mos postop & $26.88 \pm 12.95$ & $29.20 \pm 13.15$ & \\
\hline 24 mos postop & $18.31 \pm 8.94$ & $21.24 \pm 4.67$ & \\
\hline \multicolumn{3}{|l|}{ Cobb Angle } & $<0.001$ \\
\hline Preop & $9.7^{\circ} \pm 3.77$ & $9.2^{\circ} \pm 3.86$ & \\
\hline $24 \mathrm{~h}$ postop & $3.38^{\circ} \pm 1.65$ & $3.39^{\circ} \pm 1.66$ & \\
\hline 3 mos postop & $3.35^{\circ} \pm 3.16$ & $3.37^{\circ} \pm 3.19$ & \\
\hline 6 mos postop & $3.24^{\circ} \pm 2.12$ & $3.31^{\circ} \pm 2.13$ & \\
\hline 12 mos postop & $3.19^{\circ} \pm 2.09$ & $3.26^{\circ} \pm 2.06$ & \\
\hline 24 mos postop & $3.06^{\circ} \pm 2.04$ & $3.07^{\circ} \pm 2.01$ & \\
\hline Functional disability after $3 \operatorname{mos} \dagger$ & & & $<0.001$ \\
\hline 0-20\%: Minimal & $14(31.8 \%)$ & $11(25 \%)$ & \\
\hline 21-40\%: Moderate & $27(61.4 \%)$ & $28(63.6 \%)$ & \\
\hline $41-60 \%$ : Severe & $3(6.8 \%)$ & $5(11.4 \%)$ & \\
\hline \multicolumn{3}{|l|}{ Functional disability after 6 mos $\dagger$} & $<0.001$ \\
\hline 0-20\%: Minimal & $20(45.5 \%)$ & $17(38.6 \%)$ & \\
\hline 21-40\%: Moderate & $21(47.7 \%)$ & $23(52.3 \%)$ & \\
\hline $41-60 \%$ : Severe & $3(6.8 \%)$ & $4(9.1 \%)$ & \\
\hline \multicolumn{3}{|l|}{ Functional disability after 12 mos $\dagger$} & $<0.001$ \\
\hline 0-20\%: Minimal & $27(61.4 \%)$ & $24(54.5 \%)$ & \\
\hline 21-40\%: Moderate & $16(36.4 \%)$ & $18(40.9 \%)$ & \\
\hline $41-60 \%$ : Severe & $1(2.3 \%)$ & $2(4.5 \%)$ & \\
\hline \multicolumn{3}{|l|}{ Functional disability after 24 mos $\dagger$} & $<0.001$ \\
\hline 0-20\%: Minimal & $42(95.5 \%)$ & $39(88.6 \%)$ & \\
\hline 21-40\%: Moderate & $2(4.5 \%)$ & $4(9.1 \%)$ & \\
\hline 41-60\%: Severe & 0 & $1(2.3 \%)$ & \\
\hline
\end{tabular}


The spinal alignment and spinopelvic parameters in the patients of the 2 groups are summarized in Table 5 . There was a statistically significant difference between the preoperative and postoperative sagittal balance in the 2 groups $(P<0.05)$. Before the surgery, most of the patients in Group I (43.2\%) and in Group II (45.5\%) had negative sagittal balance. At 3 months after the surgery, the sagittal balance status of 23 patients $(52.3 \%)$ in Group I and 22 patients (50\%) in Group II changed to normal sagittal balance and the status of 6 patients (13.6\%) in Group I and 5 (11.4\%) in Group II changed to positive sagittal balance. Although pelvic incidence, pelvic tilt, sacral slope, and lumbar lordosis were significantly lower at 3 months after the surgery in the 2 groups, the scores in Group I were better than the Group II (Table 5).

The number of levels fused was 197 segments in the Group I and 198 segments in the Group II. Table 6 shows the frequency of the patients with good, fair and bad fusion in Groups I and II at 3, 6, 12, and 24 months after the surgery. There was no significant correlation between the number of fusion levels and functional outcome of the patients in the 2 groups.
Five patients (11.4\%) in Group I had loss of Cobb angle correction at 12 months after the surgery, of whom 4 patients were treated with short-segment fusion and 1 patient was treated with long-segment fusion. Eight patients (18.2\%) in Group II had loss of Cobb angle correction at 12 months after the surgery, of whom 6 patients were treated with short-segment fusion and 2 patients were treated with long-segment fusion. However, the relation between the angle changes and the fused levels was not significant. At 24 months of follow-up, loss of Cobb angle correction was observed in 5 patients $(11.4 \%)$ in Group I and 6 patients $(13.6 \%)$ in Group II who were treated with short-segment fusion. None of the patients in each group had any new motor deficit or sphincter problem. Severe disability because of screw loosening occurred in 3 patients $(6.8 \%)$ at 3 months, $3(6.8 \%)$ at 6 months, and $1(2.3 \%)$ at 12 months after the surgery in Group I and in 5 patients $(11.4 \%)$ at 3 months, $4(9.1 \%)$ at 6 months, $2(4.5 \%)$ at 12 months, and $1(2.3 \%)$ at 12 months postoperatively in Group II so these patient underwent reoperation. Table 7 shows postoperative complications in the 2 groups.

Table 5. Lumbar spine alignment parameters measured on standing thoracolumbosacral radiographies in the patients before and 3 months after the surgery in Groups I and II.

\begin{tabular}{|c|c|c|c|}
\hline Parameters & Preop & 3 Months Postop & $P$-value \\
\hline \multicolumn{4}{|l|}{ Group I } \\
\hline Pelvic incidence & $53.2^{\circ} \pm 6.7$ & $46.1^{\circ} \pm 6.2$ & $<0.05$ \\
\hline Pelvic tilt & $17.8^{\circ} \pm 2.9$ & $12.9^{\circ} \pm 2.3$ & $<0.05$ \\
\hline Sacral slope & $35.4^{\circ} \pm 4.3$ & $33.2^{\circ} \pm 4.1$ & $<0.05$ \\
\hline Lumbar lordosis & $63.2^{\circ} \pm 5.7$ & $56.1^{\circ} \pm 5.4$ & $<0.05$ \\
\hline \multicolumn{3}{|l|}{ Sagittal balance } & \multirow{4}{*}{$<0.05$} \\
\hline Normal $(-4$ to +4$)$ & $7(15.9 \%)$ & $30(68.2 \%)$ & \\
\hline Positive $(>+4)$ & $18(40.9 \%)$ & $12(27.3 \%)$ & \\
\hline Negative $(<-4)$ & $19(43.2 \%)$ & $2(4.5 \%)$ & \\
\hline \multicolumn{4}{|l|}{ Group II } \\
\hline Pelvic incidence & $63.3^{\circ} \pm 5.5$ & $51.8^{\circ} \pm 5.2$ & $<0.05$ \\
\hline Pelvic tilt & $19.8^{\circ} \pm 3.6$ & $14.2^{\circ} \pm 3.2$ & $<0.05$ \\
\hline Sacral slope & $43.5^{\circ} \pm 4.7$ & $37.6^{\circ} \pm 4.4$ & $<0.05$ \\
\hline Lumbar lordosis & $73.3^{\circ} \pm 7.3$ & $61.8^{\circ} \pm 6.4$ & $<0.05$ \\
\hline \multicolumn{3}{|l|}{ Sagittal balance } & \multirow{4}{*}{$<0.05$} \\
\hline $\operatorname{Normal}(-4$ to +4$)$ & $10(22.7 \%)$ & $32(72.7 \%)$ & \\
\hline Positive $(>+4)$ & $14(31.8 \%)$ & $9(20.5 \%)$ & \\
\hline Negative $(<-4)$ & $20(45.5 \%)$ & $3(6.8 \%)$ & \\
\hline
\end{tabular}

Values are expressed as mean \pm SD unless stated as frequency and percents. 
Pain Physician: July/August 2018: 21:383-406

Table 6. Frequency of the patients with good, fair, and bad fusion in Groups I and II.

\begin{tabular}{|c|c|c|c|}
\hline \multirow[t]{2}{*}{ Groups } & \multicolumn{2}{|c|}{ Fusion } & \multirow{2}{*}{$P$-value } \\
\hline & Good & Fair + bad & \\
\hline \multicolumn{3}{|l|}{ Group I } & $<0.001$ \\
\hline 3 mos postop & $19(43.2 \%)$ & $25(56.8 \%)$ & \\
\hline 6 mos postop & $23(52.3 \%)$ & $21(47.7 \%)$ & \\
\hline 12 mos postop & $30(68.2 \%)$ & $14(31.8 \%)$ & \\
\hline 24 mos postop & $35(79.5 \%)$ & $9(20.5 \%)$ & \\
\hline \multicolumn{3}{|l|}{ Group II } & $<0.001$ \\
\hline 3 mos postop & $22(50 \%)$ & $22(50 \%)$ & \\
\hline 6 mos postop & $27(61.4 \%)$ & $17(38.6 \%)$ & \\
\hline 12 mos postop & $34(77.3 \%)$ & $10(22.7 \%)$ & \\
\hline 24 mos postop & $39(88.6 \%)$ & $5(11.4 \%)$ & \\
\hline
\end{tabular}

Table 7. Complications in the 2 groups after the surgery.

\begin{tabular}{|c|c|c|c|}
\hline Complications & $\begin{array}{l}\text { Group I } \\
(\mathrm{n}=44)\end{array}$ & $\begin{array}{l}\text { Group II } \\
(n=44)\end{array}$ & Treatment \\
\hline \multicolumn{3}{|l|}{ Pseudoarthrosis } & Underwent reoperation for the angle correction \\
\hline 3 mos postop & $1(2.3 \%)$ & 0 & \\
\hline 6 mos postop & $1(2.3 \%)$ & $2(4.5 \%)$ & \\
\hline 12 mos postop & $1(2.3 \%)$ & $1(2.3 \%)$ & \\
\hline 24 mos postop & 0 & 0 & \\
\hline \multicolumn{4}{|l|}{ Wound infection } \\
\hline 3 mos postop & $1(2.3 \%)$ & $1(2.3 \%)$ & \\
\hline 6 mos postop & $2(4.5 \%)$ & $1(2.3 \%)$ & \\
\hline 12 mos postop & $2(4.5 \%)$ & $3(6.8 \%)$ & \\
\hline 24 mos postop & 0 & 0 & \\
\hline \multicolumn{3}{|l|}{ Durotomy } & Managed with simple repairing of the dura \\
\hline 3 mos postop & 0 & $1(2.3 \%)$ & \\
\hline 6 mos postop & $2(4.5 \%)$ & $2(4.5 \%)$ & \\
\hline 12 mos postop & $1(2.3 \%)$ & $1(2.3 \%)$ & \\
\hline 24 mos postop & 0 & 0 & \\
\hline \multicolumn{4}{|l|}{ Adjacent segment disease } \\
\hline \multicolumn{3}{|c|}{ Developed mild coronal and sagittal plane imbalance } & $\begin{array}{l}\text { Responded to the conservative treatment so they did } \\
\text { not undergo surgery }\end{array}$ \\
\hline 3 mos postop & $1(2.3 \%)$ & $2(4.5 \%)$ & \\
\hline 6 mos postop & $1(2.3 \%)$ & 0 & \\
\hline 12 mos postop & $4(9.1 \%)$ & $3(6.8 \%)$ & \\
\hline 24 mos postop & $1(2.3 \%)$ & $2(4.5 \%)$ & \\
\hline \multicolumn{3}{|l|}{ Developed PJK at L2 } & $\begin{array}{l}\text { Underwent surgical intervention and extended } \\
\text { fusion from T12 to S1. }\end{array}$ \\
\hline 3 mos postop & 0 & 0 & \\
\hline 6 mos postop & $2(4.5 \%)$ & $1(2.3 \%)$ & \\
\hline 12 mos postop & $2(4.5 \%)$ & $2(4.5 \%)$ & \\
\hline 24 mos postop & $1(2.3 \%)$ & $1(2.3 \%)$ & \\
\hline
\end{tabular}

$\mathrm{PJK}$ indicates proximal junctional kyphosis. 


\section{Discussion}

Because an improvement in LBP and functional ODI in patients with LSS and degenerative instability is very important, for patients with intolerable pain who fail conservative therapies and minimally invasive treatments, surgery is indicated $(32,33)$. Instrumentassisted PLF and instrument-assisted PLIF are the 2 most common techniques for the surgical treatment of LSS and degenerative instability. Various other minimallyinvasive techniques such as extreme lateral interbody fusion/direct lateral interbody fusion, and transforaminal lumbar interbody fusion are also commonly used for fusion, but there is a remarkable paucity of literature to compare the outcomes of PLF with PLIF to support which surgical technique provides more improvement of pain and disability. PLIF has been widely used in the treatment of lumbar degenerative disease since this method was first described by Cloward (34). PLIF offers several theoretical advantages: restoration of load-bearing capacity to the ventral spinal column, indirect decompression of the foramen, maintenance of the height of the intervertebral disc, and restoration of lordosis. However, some authors have stated that PLIF is difficult due to increased bleeding, prolonged duration of surgery, and more extensive dissection and that PLF is more advantageous with a lower complication risk and fewer technical demands $(35,36)$. In this study, our findings suggest that PLF with posterior instrumentation provides better clinical outcomes and improvement in the LBP, radicular pain, and functional QOL, more correction of the Cobb angle, more decrease in modic Type 1 , and more increase in modic Type 0 (normal) at 3, 6, 12 , and 24 months of follow-up, despite the low fusion rate compared to PLIF with posterior instrumentation. In addition, PLF was associated with more restoration of sagittal alignment at 3 months postoperatively in the adult population. Similar to our findings, Weber et al (37) conducted a survey study to capture potential diversities in surgeons' surgical management of LSS in Norway and their results showed that PLF was much better than PLIF.

Postoperative pain relief provides benefits such as earlier mobilization, shorter hospital stay, reduced hospital costs, and morbidity reduction. Although the goal of treatment of spinal stenosis is to decompress the affected neural structure, it is difficult to reduce back pain and neurological symptoms by decompression without performing fusion surgery in the patients who have multilevel foraminal stenosis with back pain. The findings of our study showed that the improvement in
LBP during the follow-up was significantly more in the patients who were operated on using PLF with posterior instrumentation than in the patients operated on with PLIF with posterior instrumentation and more LBP was seen in the patients of Group II after the operation. The results in our study are somewhat in contrast to other studies showing that there is a similar outcome between PLF and PLIF (13-15,38-43). Ekman et al (39) compare the outcome of PLIF and PLF in adult isthmic spondylolisthesis (IS) and reported that type of fusion, PLIF or PLF, does not affect the pain at 2 years after surgical treatment of adult IS. In a multicenter randomized study with a 2-year follow-up period, Fritzell et al (40) showed that all the fusion techniques used in their study (PLF, PLF combined with variable screw placement, and PLF combined with variable screw placement and interbody fusion) could reduce pain. In a retrospective study, Audat et al (13) compared the clinical outcomes of PLF and PLIF and reported that PLF and PLIF are equally suitable for treating degenerative disc disease and there is no difference in the VAS score between these techniques. Zhou et al (38) compared the effectiveness of instrumented PLIF and instrumented PLF for the treatment of LBP due to degenerative lumbar disease and their findings showed that there were no significant differences between these 2 techniques concerning the improvement in LBP. Kim et al (41) could not demonstrate any difference in outcome between PLIF and PLF in a mixed patient material, including spinal stenosis as well as degenerative and IS. Cheng et al (14) compared the clinical outcome of PLIF and PLF in spondylolisthesis and they reported that there was no significant statistical difference between the VAS scores in the 2 groups. Lidar et al (42) reported that there was no difference regarding VAS between the 2 groups. However, in contrast to our findings, some studies have reported that PLIF provides more reduction in VAS than PLF $(15,43)$. In 2015, Alijani et al (15) evaluated and compared the pain of patients with spondylolisthesis who had undergone either PLF or PLIF and they reported that PLIF was related to better outcome with respect to pain control at 6 month after the surgery than PLF. Similarly, Aygün et al (43) reported that at 48 months after the surgery, PLIF group showed better results regarding VAS than the PLF group. The difference between Aygün et al's findings (43) with our findings might be due to their longer follow-up period that was twice more than that of our study.

Usually, radicular pain post laminectomy relieves immediately after the surgery (at the first 24 hours after 
the surgery) due to successful nerve root decompression (44-46). LBP results from the manipulation of soft tissue, muscles and facet joints and decreases gradually during the first few weeks or months after surgery (31). In our patients, both LBP and radicular pain were reduced more in the PLF group than the PLIF group during the follow-up period, and consequently, when the pain reduces, the patients' social burden will decrease and the patients can return to work or other normal functions. Kim et al (41) reported that both PLF and PLIF reduced radiating pain in the leg. However, some studies (47) have reported that the postoperative leg pain has been a disadvantage of PLIF because the nerve root and thecal sac are retracted excessively when inserting a cage or bone graft. Dantas et al (48) reported that the improvement in radicular pain was $82 \%$ in the PLF group and $85.5 \%$ in the PLIF group which shows that PLIF was associated with more improvement in the radicular pain than the PLF in their study. In our study, posterior decompression of spinal canal and nerve roots was performed as much as possible. Neurogenic claudication is a clinical syndrome due to LSS, or inflammation of the nerves emanating from the spinal cord. Neurogenic means that the problem originates from a nerve, and claudication, from the Latin for limp, describes the painful cramping or weakness in the legs (6). Dantas et al (48) observed neurogenic claudication in 19 patients $(63.3 \%)$ in the PLF group, and in 11 patients $(36.6 \%)$ in the PLIF group, and reported that it was improved in all cases. Interestingly, in our study, despite posterior decompression of spinal canal and nerve roots that was performed completely in the two groups, the number of patients who had complaints of neurogenic claudication was significantly reduced in the 2 groups, but the number of patients with neurogenic claudication was more in the PLIF group with posterior instrumentation than in the PLF group with posterior instrumentation at 12 and 24 months. In our study, no patient in the PLF group had complaints of neurogenic claudication at 12 and 24 months of follow-up.

An increase in life expectancy will lead to an increase in spinal pathologies with evermore pressing requests on the part of patients for an improvement in functional QOL. The findings of our study showed that PLF with posterior instrumentation is more appropriate for the improvement of the functional QOL than the PLIF with posterior instrumentation as the decrease in the ODI scores in the PLF group was more than the PLIF group at 3, 6, 12, and 24 months after the surgery. Similar to our findings, some studies (35) have reported that the ODI score in patients who underwent PLF was decreased more than that of patients who were treated with PLIF. Wu et al (49) evaluated the ODI in the PLF group versus PLIF group in patients with lumbar degenerative disease. Their findings showed that the preoperative mean ODI score in the PLF group was 34.5 which reduced to 14.2 at the final follow-up (mean reduction $=20.3$ ) and the mean preoperative ODI in the PLIF group was 36.4 which reduced to 16.2 at the final follow-up (mean reduction $=20.2$ ). However, our findings showed that the mean reduction in the ODI score at the final follow-up for Groups I and II was twice more than the mean reduction reported by $\mathrm{Wu}$ et al (49) (42.75 vs. 40.94, respectively). In a prospective observational study in 2015, Alijani et al (15) documented that both surgical fusion techniques (PLF and PLIF) were efficient to lessen the disability of patients with spondylolisthesis, and none of the fusion techniques were related to a better outcome in terms of disability after 1-year of follow-up. Similarly, Lidar et al (42) and Ekman et al (39) showed that that there was no improvement on patient ODI in the PLIF group compared with PLF and there was no difference regarding ODI between the two groups. However, similar to our study, Madan and Boeree (35) evaluated the outcomes PLF and PLIF for low grades of IS and their results in a minimum follow-up period of 2.1 years showed that the clinical satisfactory outcome on the ODI was $81 \%$ for PLF and $69 \%$ for PLIF and they concluded that PLF has a better clinical outcome in low grades of IS than PLIF. The results in our study are in contrast to a study conducted by Habib (16) in 2014 in which the author used ODI to study disability in 50 patients with lumbar IS and demonstrated a significant better long term ODI in PLIF group in a follow-up of 18 months.

Although the efficacy of fusion in degenerative disease remains controversial, several studies have recommended instrumentation to improve the fusion rate (9). Furthermore, spinal fusion may prevent recurrent stenosis. Some studies have reported the same fusion rate in PLF and PLIF groups (50). Similarly to the findings of most studies (50) who reported that fusion rate in the PLIF is more than PLF, we found higher fusion rates in patients who underwent PLIF rather than PLF with posterior instrumentation. It could be due to more fusion bed and performing fusion under compression (Wolff's law), which was closer to the normal physiology of load-bearing of the anterior spinal column. In a randomized controlled trials conducted by Zhou et al (38), authors provided the evidence that instrumented 
PLIF has an advantage of higher fusion rate over instrumented PLF. Similar to our findings, Lidar et al (42) and Cheng et al (14) showed that the PLIF group presented a better fusion rate than the PLF group. Suk et al (51) retrospectively analyzed 76 patients with spondylolisthesis who underwent instrumented PLF vs. patients who underwent PLIF combined with instrumented PLF and they reported that the fusion rate in the PLIF group was $100 \%$ vs. $87.5 \%$ in the PLF group. They also showed that the excellent outcome portion was $75 \%$ in the PLIF group compared with $45 \%$ in the PLF group (51), but our findings showed that the patients in the PLF group had better clinical outcomes than the patients in the PLIF group. Madan and Boeree (35) compared the outcome of PLF vs. PLIF combined with instrumented PLF in patients with grades 1 and 2 spondylolisthesis. Similar to our findings, they reported that fusion rates were better for the PLIF group than the PLF group (35), but clinical outcome was better for the PLF group. Fritzell et al (40) prospectively studied 222 patients with chronic back pain and disc degeneration who were randomized into 1 of 3 fusion procedures: PLF with transpedicular fixation, PLF without instrumentation, and PLIF combined with instrumented PLF and they reported a $91 \%$ fusion rate for PLIF, $87 \%$ for instrumented PLF, and $72 \%$ for noninstrumented PLF after a follow-up period of 2 years.

The sagittal balance status and spinopelvic parameters are key components in the evaluation and treatment of degenerative pathologies of the spine. It is believed that the surgical planning should be based on the sagittal alignment $(44,52)$. Farrokhi et al (33) emphasized that it is necessary to evaluate the sagittal balance and spinopelvic parameters completely before the surgery in the patients with LSS. However, few studies have quantitatively measured the spinal sagittal parameters in patients with LSS or degenerative lumbar spine instability $(33,53)$. The spinopelvic morphology modulates the lumbosacral configuration and consequently, the mechanical stress at the lumbosacral junction. Restoration of the sagittal balance has been emphasized recently $(33,54)$ and it has been shown to directly impact both the standing balance and clinical outcomes of the patients $(54,55)$. Kawakami et al $(56)$ studied whether lumbar sagittal balance affected the clinical outcome after PLF and they concluded that SVA (center in the L1 to the back corner of the S1) should be considered in the choice of treatment strategy when PLF is indicated for patients with degenerative lumbar spondylolisthesis. In this study, we compared pre- and post-operative measurements of sagittal balance between the 2 groups and our findings showed that the sagittal balance and spinopelvic parameters were all improved significantly at 3 months after the surgery in the 2 groups and this improvement was also associated with good clinical outcome, but PLF group did better than the PLIF group. Our finding are in consistent with a study conducted by Korovessis et al (53) in which the authors evaluated the effect of sagittal spinal balance on LBP in patients underwent decompression and instrumented PLF for degenerative lumbar spine disease and suggested that the methods directed at the improvement in sagittal spinal balance of the lumbar spine might be beneficial for decreasing LBP after surgery in degenerative lumbar spine disease. Clinical studies have demonstrated that interbody fusion grafts are associated with high fusion rates and improvement in sagittal balance (57). However, although our findings showed that PLIF was associated with a higher fusion rate, the improvement in sagittal balance and spinopelvic parameters was more in the PLF group than the PLIF group at 3 months postoperatively. In contrast to our findings, Zhou et al (38) reported that in the patients with degenerative lumbar disease, instrumented PLIF is associated with better restoration of spinal alignment over instrumented PLF. Similarly, In a prospective randomized study on degenerative lumbar disease, Kim et al (41) documented that PLIF had better sagittal balance than PLF. Moreover, Musluman et al. (58) reported that PLIF could achieve better sagittal balance and that the back pain VAS scores were improved from the early postoperative period to the final follow-up. However, in our study, the patients in the PLF group had better sagittal balance and more reduction in VAS scores than the patients in the PLIF group. Similar to our findings, some authors have reported that the clinical results of PLIF are not superior than PLF in the treatment of lowgrade spondylolisthesis $(14,41,48,58)$, although PLIF is expected to achieve better maintenance of correction and bony union. In addition, Kuraishi et al (50) reported that lumbar lordosis in the PLIF group was not better than that in the PLF group, which might be due to the lack of difference in clinical outcomes between the 2 groups.

The pain resulting from modic changes of endplate belongs to the discogenic LBP. So, in the assessment of LBP for patients with LSS and degenerative lumbar spine instability, we must comprehensively analyze and pay attention to the existence and distribution of modic changes. It has been reported that among 
modic changes, Type 1 changes are the ones most strongly associated with LBP and segmental instability, thus reflecting a state of active degeneration and biomechanical instability of the lumbar spine (59). In contrast, Type 2 changes are less clearly associated with LBP and seem to indicate a more biomechanically stable state (59). The natural history of modic changes in the lumbar spine is often marked by conversion from one type to another (60). Some studies suggest that fusion increases the conversion of modic changes Type 1 to modic changes Type 2, probably by correcting the mechanical instability, and these changes appear to be a good indicator of satisfactory outcome after fusion surgery (61). Vital et al (62) demonstrated that all Type 1 changes converted into either Type 2 changes or back to normal within 6 months following lumbar fusion, which paralleled clinical improvement in all patients. Rahme et al (60) reported that neither the preoperative presence of modic changes nor their postoperative course appears to affect the clinical outcome. However, in our study, the patients in the 2 groups experienced a significant improvement in VAS and ODI that might be due to a significant decrease in modic Type 1 and an increase in modic Type 0 in our patients at 12 and 24 months of follow-up. However, PLF group had more decrease in modic Type 1 and more increase in modic Type 0 and consequently the mean reduction in VAS and ODI in the PLF group was more than the PLIF group. Similar to our findings, Mitra et al (63) found a positive trend between the evolution of Type 1 modic changes into Type 2 changes and the improvement of symptoms and suggested that if the Type 1 lesion does convert to Type 2 , it starts to do so within 2 years in most cases. Similar to other studies (64), in our study Type 2 changes were the most frequent in the 2 PLF and PLIF groups. It is believed that superimposed changes such as continued or accelerated degeneration may induce inflammation in Type 2 lesions leading to their reverse conversion to Type 1 (64), but no modic Type 2 lesion converted to Type 1 in the 2 groups in our study. To our knowledge, this is the first study in the literature, which compares the modic changes between the 2 groups of PLF and PLIF in patients with LSS and degenerative lumbar spine instability.

One of the major issues after lumbar spinal fusion is the development of adjacent segment disease (ASD) (65). Degeneration that develops at mobile segments above or below a fused spinal segment is known as ASD (66). Adjacent segment degeneration is not always associated with severe complaints and only a part of these patients required revision surgery. Korovessis et al (53) reported that none of the $3(6 \%)$ patients in their study, who developed radiologic ASD needed additional surgery until the final observation. In our study, there was no significant difference in the incidence of ASD between the 2 groups. Our findings are inconsistent with a study conducted by Aygün et al (43) in which they showed that the occurrence of adjacent segment pathologies after these 2 fusion techniques was similar. In contrast to our findings, Lee et al (67) studied a consecutive series of 490 patients who had undergone lumbar spinal fusion (103 were treated with PLF and 387 were treated with PLIF) of 3 or fewer segments to treat degenerative lumbar disease and they showed that biomechanically, PLIF is more rigid than PLF, and therefore, patients who undergo PLIF are suspected to experience a higher incidence of ASD than those who underwent PLF. Suk et al (51) recommended the PLIF procedure because PLF was associated with more cases of pseudoarthrosis while PLIF has preferable characteristics such as anterior column support, maintenance of reduction, and a better fusion rate. In our study the number of the patients with pseudoarthrosis in the 2 groups was the same at 12 and 24 months after the surgery ( 1 and 0 , respectively). Although Suk et al (51) recommended the PLIF procedure is better, Ekman et al (39) found significantly more complications in patients operated on with PLIF. The PLIF technique is more invasive, technically more demanding, and results in a longer operating time and a larger blood loss, factors all increasing the risk of complication (35). Many studies have reported that some complications associated with the PLIF procedure are permanent neurological deficit, cerebrospinal fluid leakage, radicular pain, and deep wound infection $(47,68)$. Our results are inconsistent with the findings reported in a study by Zhou et al (38) in which they showed that there were no significant differences between instrumented PLIF and instrumented PLF concerning the complication rate in patients with degenerative lumbar disease. In addition to sagittal balance, clinical outcomes of instrumented PLF or instrumented PLIF in patients with degenerative lumbar spine disease may be influenced by a variety of pathophysiologic factors, including residual compression of the neural tissues, recurrence of spinal canal stenosis, irreversible changes to the nerve root, or cauda equine, but none of our patients in each group showed any of these pathophysiologic factors at 12 and 24 months postoperatively.

Wide decompression and fusion may be accompa- 
nied by substantial complications such as postoperative blood loss, a prolonged operation time and postoperative infection. Further, long segment fusion and abundant blood loss may increase the incidences of complications. Excessive bleeding, often requiring multiple blood transfusions, can cause not only hemodynamic changes, but also fever and complications following the injection of allogenic blood (22). Zhou et al (38) showed that there were no significant differences between instrumented PLIF and instrumented PLF concerning the blood loss. In contrast, Kim et al (41) showed that PLIF had advantages of shorter operating time and less blood loss than PLF in their study. However, our results showed that the patients who underwent PLF with posterior instrumentation had significantly shorter surgical time and less intraoperative blood loss than those who were treated with PLIF with posterior instrumentation. Similar to our findings, Cloward (69) reported that despite increased the fusion rate of the PLIF technique, it was associated with complications related to blood loss.

Our findings showed that the mean Cobb angle changed significantly from $9.7^{\circ}$ preoperatively to $3.06^{\circ}$ at the last follow-up in the PLF group and from $9.2^{\circ}$ preoperatively to $3.07^{\circ}$ at the last follow-up in the PLIF group. The mean of Cobb angle correction rate in our study after 12 and 24 months of follow-up in the PLF group (6.51 and 6.64, respectively) was significantly higher than a mean value of correction in the PLIF group (5.94 and 6.13, respectively) so our findings show that PLF technique is more associated with Cobb angle correction rate than the PLIF. To our knowledge, this is the first study in the literature which has compared the Cobb angle in the patients who underwent either PLF with posterior instrumentation or PLIF with posterior instrumentation after lumbar decompression surgery for LSS and degenerative lumbar spine instability. Therefore, we could not compare and contrast our findings regarding the Cobb angle with other studies on this ground in the literature. We suggest that future studies are warranted to further investigate the Cobb angle in these patients.

In our study, the number of women presented with worse LBP, radicular pain, and ODI preoperatively was 3 times more than the number of men (66 vs. 22, respectively), but women in our 2 groups improved more than men after the surgery. Previous studies have shown mixed results pertaining to gender-based differences in the prevalence of LSS due to differences in methodology (70). Considering gender differences in pain perception, there are likely differences in pain responses between men and women with LSS (71). Women patients more often present with increased low back and radiating leg pain (72) and display a higher level of disability (73) and health-care seeking (74) than men. Previous studies have suggested possible mechanisms for the variation in pain perception between men and women with LSS (71), which have been portrayed as either biological, such as hormonal differences, or psychological $(72,75,76)$. Ishimoto et al (77) investigated the prevalence of symptomatic LSS in 1,009 patients of whom two-thirds were women and reported that with increasing age in both genders, the prevalence of symptomatic LSS for women was higher than that of men. Similarly, other studies indicated that elderly women tend to have more severe lumbar disc degeneration than elderly men (78). Consistent with a study conducted by Shabat et al (75), the 2 studies published by Kim et al $(71,76)$ in Pain Physician Journal also showed that women with degenerative LSS had a higher VAS for back pain/leg pain and ODI than men with degenerative LSS after adjustment for BMI, age, and the grade of canal stenosis/disc degeneration. This finding indicates that women suffer more from LSS compared to men, despite similar grades of canal stenosis and disc degeneration (71). Therefore, this might explain why women more frequently undergo lumbar fusion surgery than men $(77,79)$ and why in our study, the 2 fusion groups had nearly 3 times as many women as men. Some studies have shown that women tend to have a poorer outcome after spine surgery than men (76). Lehto et al (80) and McCullen et al (81) reported a worse outcome in women in response to the treatment of spinal stenosis, while studies on patients with lumbar disc herniation or sciatica have shown contradictory results $(82,83)$. Strömqvist et al $(84)$ observed that men and women showed similar levels of satisfaction with the treatment result, whereas Shabat et al (75) and Gepstein et al (85) reported that men showed greater postoperative satisfaction than did women, with this being explained by their higher preoperative expectations. Wise et al (86) found men to have a higher threshold for thermal pain and a greater pain tolerance than do women. Thus, men may report lower pain even though they experience similar pain stimuli as women-biasing most previously published results assessing pain after lumbar fusion surgery. However, in a study conducted by Triebel et al (87) in 2017, the authors investigated whether gender affects clinical outcome after lumbar fusion. They studied the 2-year follow-up results from 4,780 prospectively collected patients in the Swedish 
National Spine Register with lumbar degenerative disc disease and chronic LBP and their findings showed that women do not have worse results than men after spinal fusion surgery. Similar to our findings, they also reported that women patients present with worse pain and function preoperatively, but improve more than men do after surgery (87). In their cohort of Swedish men and women (87), gender did not seem to be of importance in the decision whether to operate on a patient. In 2016, Pochon et al (88) examined the influence of gender on baseline status and 1-year postoperative outcomes in a large series of patients undergoing surgery for different degenerative spinal disorders (including spinal stenosis) and showed that women do not differ significantly from men regarding their postoperative outcome, even though they present with a worse preoperative status. They also reported that the management of a patient's condition should not differ depending on their gender, since both men and women are able to improve to a similar extent (88).

We had some limitations in this study. There are few prospective studies of PLIF or PLF in patients with LSS and degenerative lumbar spine instability, and a limited number of studies which exists have examined the safety and outcome of each procedure without comparing it with other fusion techniques. Because most of the studies in the literature have been conducted in the patients with IS, we could not compare and contrast our findings with studies in patients with LSS and degenerative lumbar spine instability. In addition, although in our study the findings at a 24-month follow-up period showed that PLF was better than PLIF in these patients, there were some studies in the literature like Aygün et al's study (43) in which the authors reported that PLIF showed better clinical results than PLF at a 48-month follow-up period. So we suggest that rigorous controlled trials at longer follow-up periods should be undertaken in groups of patients with LSS and degenerative lumbar spine instability who undergo posterior decompression and instrumented fusion to help to determine the ultimate best fusion technique for these patients.

\section{Conclusion}

Compared with PLIF, PLF with posterior instrumentation in patients with LSS and degenerative lumbar spine instability provides better clinical outcomes and improvement in the LBP, radicular pain, and functional QOL, more correction of the Cobb angle, more decrease in modic Type 1, and more increase in modic Type 0 (normal). In this study, PLF is also recommended because the procedure is simple and has less blood loss. Moreover, this study presents the spinal sagittal balance and the spinopelvic parameters in the adult population and documents that posterior lumbar decompression with PLF is associated with more restoration of sagittal alignment, resulting in an increase in the patients' clinical outcomes. PLIF is associated with more fusion rate than PLF.

\section{Acknowledgment}

The present article was extracted from the thesis written by Golnaz Yadollahikhales and was financially supported by Shiraz University of Medical Sciences (Grant No. 91-01-01-4438). The authors thank Ms. Hosseini from Shiraz Neuroscience Research Center for her assistance.

\section{References}

1. Frymoyer JW, Selby DK. Segmental instability. Rationale for treatment. Spine (Phila Pa 1976) 1985; 10:280-286.

2. Leone A, Guglielmi G, Cassar-Pullicino VN, Bonomo L. Lumbar intervertebral instability: A review. Radiology 2007; 245:62-77.

3. Kirkaldy-Willis WH, Farfan HF. Instability of the lumbar spine. Clin Orthop Relat Res 1982; (165):110-123.

4. Schroeder GD, Kurd MF, Vaccaro AR. Lumbar spinal stenosis: How is it classified? J Am Acad Orthop Surg 2016; 24:843-852.
5. Weinstein JN, Tosteson TD, Lurie JD, Tosteson AN, Blood E, Hanscom B, Herkowitz $H$, Cammisa F, Albert $T$, Boden SD, Hilibrand A, Goldberg $H$, Berven S, An H; SPORT Investigators. Surgical versus nonsurgical therapy for lumbar spinal stenosis. $N$ Engl ] Med 2008; 358:794-810.

6. Comer CM, Redmond AC, Bird HA, Conaghan PG. Assessment and management of neurogenic claudication associated with lumbar spinal stenosis in a UK primary care musculoskeletal service: A survey of current practice among phys- iotherapists. BMC Musculoskelet Disord 2009; 10:121.

7. Seong YJ, Lee JS, Suh KT, Kim JI, Lim JM, Goh TS. Posterior decompression and fusion in patients with multilevel lumbar foraminal stenosis: A comparison of segmental decompression and wide decompression. Asian Spine J 2011; 5:100-106.

8. Deyo RA, Mirza SK, Martin BI, Kreuter W, Goodman DC, Jarvik JG. Trends, major medical complications, and charges associated with surgery for lumbar spinal stenosis in older adults. JAMA 2010; 
303:1259-1265.

9. Cassinelli EH, Eubanks J, Vogt M, Furey C, Yoo J, Bohlman $\mathrm{HH}$. Risk factors for the development of perioperative complications in elderly patients undergoing lumbar decompression and arthrodesis for spinal stenosis: An analysis of 166 patients. Spine (Phila Pa 1976) 2007; 32:230-235.

10. Farrokhi MR, Gholami M. A letter to the editor regarding "Fusion or not for degenerative lumbar spinal stenosis: A meta-analysis and systematic review". Pain Physician 2018; 21:E284-E287.

11. Farrokhi MR, Jamali M, Gholami M, Farrokhi F, Hosseini K. Clinical and radiological outcomes after decompression and posterior fusion in patients with degenerative scoliosis. Br J Neurosurg 2017; 31:514-525.

12. Bae HW, Rajaee SS, Kanim LE. Nationwide trends in the surgical management of lumbar spinal stenosis. Spine (Phila Pa 1976) 2013; 38:916-926.

13. Audat Z, Moutasem O, Yousef K, Mohammad $B$. Comparison of clinical and radiological results of posterolateral fusion, posterior lumbar interbody fusion and transforaminal lumbar interbody fusion techniques in the treatment of degenerative lumbar spine. Singapore Med J 2012; 53:183-187.

14. Cheng L, Nie L, Zhang L. Posterior lumbar interbody fusion versus posterolateral fusion in spondylolisthesis: A prospective controlled study in the Han nationality. Int Orthop 2009; 33:1043-1047.

15. Alijani B, Emamhadi M, Behzadnia $\mathrm{H}$, Aramnia A, Chabok SY, Ramtinfar S, Leili EK, Golmohamadi S. Posterior lumbar interbody fusion and posterolateral fusion: Analogous procedures in decreasing the index of disability in patients with spondylolisthesis. Asian J Neurosurg 2015; 10:51.

16. Habib HA. Posterolateral fusion versus posterior interbody fusion in adult lumbar isthmic spondylolisthesis. Menoufia Med ] 2014; 27:191-196.

17. Modic MT, Steinberg PM, Ross JS, Masaryk TJ, Carter JR. Degenerative disk disease: Assessment of changes in vertebral body marrow with MR imaging. Radiology 1988; 166:193-199.

18. Morrissy RT, Goldsmith GS, Hall EC, Kehl D, Cowie GH. Measurement of the Cobb angle on radiographs of patients who have scoliosis. Evaluation of intrinsic error. J Bone Joint Surg Am 1990; 72:320-327.
19. Jackson RP, McManus AC. Radiographic analysis of sagittal plane alignment and balance in standing volunteers and patients with low back pain matched for age, sex, and size. A prospective controlled clinical study. Spine (Phila $\mathrm{Pa}$ 1976) 1994; 19:1611-1618.

20. Keshtkaran A, Bagheri MH, Ostovar R, Salari H, Farokhi MR, Esfandiari A, Yousefimanesh $H$. Developing criteria for lumbar spine magnetic resonance imaging (MRI) using RAND appropriateness method (RAM). Iran J Radio 2012; 9:130-138.

21. Roussouly P, Gollogly S, Berthonnaud $E$, Dimnet J. Classification of the normal variation in the sagittal alignment of the human lumbar spine and pelvis in the standing position. Spine (Phila Pa 1976) 2005; 30:346-353.

22. Farrokhi MR, Kazemi AP, Eftekharian $H R$, Akbari K. Efficacy of prophylactic low dose of tranexamic acid in spinal fixation surgery: A randomized clinical trial. J Neurosurg Anesthesiol 2011; 23:290-296

23. Farrokhi MR, Nikoo Z, Gholami M, Hosseini K. Comparison between acrylic cage and polyetheretherketone (PEEK) cage in single-level anterior cervical discectomy and fusion: A randomized clinical trial. Clin Spine Surg 2017; 30:38-46.

24. Huskisson EC. Measurement of pain. Lancet 1974; 2:1127-1131.

25. Farrokhi MR, Motallebi H. Outcome of surgical and nonsurgical methods in the treatment of unstable traumatic lesions of the lower cervical spine. Arch Iran Med 2007; 10:157-160.

26. Farrokhi MR, Lotfi M, Masoudi MS, Gholami M. Effects of methylene blue on postoperative low-back pain and functional outcomes after lumbar open discectomy: A triple-blind, randomized placebo-controlled trial. J Neurosurg Spine 2016; 24:7-15.

27. Farrokhi MR, Masoudi MS. Slipped vertebral epiphysis (report of 2 cases). J Res Med Sci 2009; 14:63-66.

28. Farrokhi MR, Yazdanpanah H, Gholami M, Farrokhi F, Mesbahi AR. Pain and functional improvement effects of methylene blue injection on the soft tissue around fusion site after traumatic thoracolumbar fixation: A double-blind, randomized placebo-controlled study. Clin Neurol Neurosurg 2016; 150:6-12.

29. Riew KD, Long J, Rhee J, Lewis S, Kuklo T, Kim YJ, Yukawa Y, Zhu Y. Time-dependent inhibitory effects of indomethacin on spinal fusion. ] Bone Joint Surg Am 2003; 85-A:632-634.

30. Fairbank JC, Pynsent PB. The Oswestry disability index. Spine (Phila Pa 1976) 2000; 25:2940-2952.

31. Quaglietta P, Cassitto D, Corriero AS, Corriero G. Paraspinal approach to the far lateral disc herniations: Retrospective study on 42 cases. Acta Neurochir Suppl 2005; 92:115-119.

32. Omidi-Kashani F, Hasankhani EG, Ashjazadeh A. Lumbar spinal stenosis: Who should be fused? An updated review. Asian Spine J 2014; 8:521-530.

33. Farrokhi MR, Haghnegahdar A, Rezaee $H$, Sharifi Rad MR. Spinal sagittal balance and spinopelvic parameters in patients with degenerative lumbar spinal stenosis; A comparative study. Clin Neurol Neurosurg 2016; 151:136-141.

34. Cloward RB. The treatment of ruptured lumbar intervertebral discs by vertebral body fusion. I. Indications, operative technique, after care. J Neurosurg 1953; 10:154-168.

35. Madan S, Boeree NR. Outcome of posterior lumbar interbody fusion versus posterolateral fusion for spondylolytic spondylolisthesis. Spine (Phila Pa 1976) 2002; 27:1536-1542.

36. Rompe JD, Eysel P, Hopf C. Clinical efficacy of pedicle instrumentation and posterolateral fusion in the symptomatic degenerative lumbar spine. Eur Spine ] 1995; 4:231-237.

37. Weber C, Lønne G, Rao V, Jakola AS, Solheim O, Nerland U, Rossvoll I, Nygaard $\varnothing P$, Peul WC, Gulati S. Surgical management of lumbar spinal stenosis: A survey among Norwegian spine surgeons. Acta Neurochir (Wien) 2017; 159:191-197.

38. Zhou ZJ, Zhao FD, Fang XQ, Zhao X, Fan SW. Meta-analysis of instrumented posterior interbody fusion versus instrumented posterolateral fusion in the lumbar spine. J Neurosurg Spine 2011; 15:295-310.

39. Ekman P, Möller H, Tullberg T, Neumann P, Hedlund R. Posterior lumbar interbody fusion versus posterolateral fusion in adult isthmic spondylolisthesis. Spine (Phila Pa 1976) 2007; 32:2178-2183.

40. Fritzell $P$, Hägg $O$, Wessberg $P$, Nordwall A; Swedish Lumbar Spine Study Group. Chronic low back pain and fusion: A comparison of three surgical techniques: A prospective multicenter randomized study from the Swedish lumbar spine study group. Spine (Phila 
Pa 1976) 2002; 27:1131-1141.

41. Kim KT, Lee SH, Lee YH, Bae SC, Suk KS. Clinical outcomes of 3 fusion methods through the posterior approach in the lumbar spine. Spine (Phila Pa 1976) 2006; 31:1351-1357.

42. Lidar Z, Beaumont A, Lifshutz J, Maiman D). Clinical and radiological relationship between posterior lumbar interbody fusion and posterolateral lumbar fusion. Surg Neurol 2005; 64:303-308.

43. Aygün $H$, Cakar A, HüseyinoDlu $N$, Hüseyino Dlu U, Celik R. Clinical and radiological comparison of posterolateral fusion and posterior interbody fusion techniques for multilevel lumbar spinal stabilization in manual workers. Asian Spine J 2014; 8:571-580.

44. Farrokhi MR, Ghaffarpasand F, Khani $M$, Gholami M. An evidence-based stepwise surgical approach to cervical spondylotic myelopathy: A narrative review of the current literature. World Neurosurg 2016; 94:97-110.

45. Farrokhi MR, Gholami M. In reply to the letter to the editor regarding 'an evidence-based stepwise surgical approach to cervical spondylotic myelopathy: A narrative review of the current literature'. World Neurosurg 2017; 98:848-849.

46. Farrokhi MR, Vasei M, Fareghbal S, Bakhtazad A. Effect of honey on peridural fibrosis formation after laminectomy in rats: A novel experimental study. Evid Based Complement Alternat Med 2011; 2011:504967.

47. Lin PM. Posterior lumbar interbody fusion technique: Complications and pitfalls. Clin Orthop Relat Res 1985; (193):90-102.

48. Dantas FL, Prandini MN, Ferreira MA. Comparison between posterior lumbar fusion with pedicle screws and posterior lumbar interbody fusion with pedicle screws in adult spondylolisthesis. Arq Neuropsiquiatr 2007; 65:764-770.

49. Wu Y, Tang H, Li Z, Zhang Q, Shi Z. Outcome of posterior lumbar interbody fusion versus posterolateral fusion in lumbar degenerative disease. J Clin Neurosci 2011; 18:780-783.

50. Kuraishi S, Takahashi J, Mukaiyama K, Shimizu M, Ikegami S, Futatsugi T, Hirabayashi $\mathrm{H}$, Ogihara $\mathrm{N}$, Hasidate $\mathrm{H}$, Tateiwa Y, Kinoshita H, Kato H. Comparison of clinical and radiological results of posterolateral fusion and posterior lumbar interbody fusion in the treatment of $\mathrm{L} 4$ degenerative lumbar spondylolisthesis. Asian Spine J 2016;
10:143-152.

51. Suk SI, Lee CK, Kim WJ, Lee JH, Cho KJ, Kim HG. Adding posterior lumbar interbody fusion to pedicle screw fixation and posterolateral fusion after decompression in spondylolytic spondylolisthesis. Spine (Phila Pa 1976) 1997; 22:210-219.

52. Dohzono S, Toyoda H, Matsumoto T, Suzuki A, Terai H, Nakamura H. The influence of preoperative spinal sagittal balance on clinical outcomes after microendoscopic laminotomy in patients with lumbar spinal canal stenosis. ] Neurosurg Spine 2015; 23:49-54.

53. Korovessis P, Repantis T, Papazisis Z, Iliopoulos P. Effect of sagittal spinal balance, levels of posterior instrumentation, and length of follow-up on low back pain in patients undergoing posterior decompression and instrumented fusion for degenerative lumbar spine disease: A multifactorial analysis. Spine (Phila Pa 1976) 2010; 35:898-905.

54. O'Shaughnessy BA, Ondra SL. Measuring, preserving, and restoring sagittal spinal balance. Neurosurg Clin N Am 2007; 18:347-356.

55. Coutinho MAC, Pratali RR, Motta MM, Hoffman CB, Barsotti CEG, Santos FPE, Soares de Oliveira CEA. Influence of the sagittal balance on the clinical outcome in spinal fusion. Coluna/Columna 2016; 15:52-56.

56. Kawakami M, Tamaki T, Ando M, Yamada $\mathrm{H}$, Hashizume $\mathrm{H}$, Yoshida M. Lumbar sagittal balance influences the clinical outcome after decompression and posterolateral spinal fusion for degenerative lumbar spondylolisthesis. Spine (Phila Pa 1976) 2002; 27:59-64.

57. Acosta FL, Liu J, Slimack N, Moller D, Fessler R, Koski T. Changes in coronal and sagittal plane alignment following minimally invasive direct lateral interbody fusion for the treatment of degenerative lumbar disease in adults: A radiographic study. J Neurosurg Spine 2011; 15:92-96.

58. Müslüman AM, Yılmaz A, Cansever T, CavuDoDlu H, Colak I, Genç HA, Aydın Y. Posterior lumbar interbody fusion versus posterolateral fusion with instrumentation in the treatment of lowgrade isthmic spondylolisthesis: Midterm clinical outcomes. J Neurosurg Spine 2011; 14:488-496.

59. Rahme R, Moussa R. The modic vertebral endplate and marrow changes: Pathologic significance and relation to low back pain and segmental instability of the lumbar spine. AJNR Am J Neuroradiol 2008; 29:838-842.

6o. Rahme R, Moussa R, Bou-Nassif R, Maarrawi J, Rizk T, Nohra G, Samaha E, Okais N. What happens to Modic changes following lumbar discectomy? Analysis of a cohort of 41 patients with a 3- to 5-year follow-up period.] Neurosurg Spine 2010; 13:562-567.

61. Laustsen AF, Bech-Azeddine R. Do Modic changes have an impact on clinical outcome in lumbar spine surgery? A systematic literature review. Eur Spine ] 2016; 25:3735-3745.

62. Vital JM, Gille O, Pointillart V, Pedram M, Bacon P, Razanabola F, Schaelderle C, Azzouz S. Course of Modic I six months after lumbar posterior osteosynthesis. Spine (Phila Pa 1976) 2003; 28:715-720.

63. Mitra D, Cassar-Pullicino VN, McCall IW. Longitudinal study of vertebral type1 end-plate changes on MR of the lumbar spine. Eur Radiol 2004; 14:1574-1581.

64. Kuisma M, Karppinen J, Niinimäki J, Kurunlahti $M$, Haapea $M$, Vanharanta $H$, Tervonen O. A three-year follow-up of lumbar spine endplate (Modic) changes. Spine (Phila Pa 1976) 2006; 31:1714-1718.

65. Lawrence BD, Wang J, Arnold PM, Hermsmeyer J, Norvell DC, Brodke DS. Predicting the risk of adjacent segment pathology after lumbar fusion: A systematic review. Spine (Phila Pa 1976) 2012; 37:S123-S132.

66. Park P, Garton HJ, Gala VC, Hoff JT, McGillicuddy JE. Adjacent segment disease after lumbar or lumbosacral fusion: Review of the literature. Spine (Phila Pa 1976) 2004; 29:1938-1944.

67. Lee JC, Kim Y, Soh JW, Shin BJ. Risk factors of adjacent segment disease requiring surgery after lumbar spinal fusion: Comparison of posterior lumbar interbody fusion and posterolateral fusion. Spine (Phila Pa 1976) 2014; 39:E339-E345.

68. Ha KY, Na KH, Shin JH, Kim KW. Comparison of posterolateral fusion with and without additional posterior lumbar interbody fusion for degenerative lumbar spondylolisthesis.] Spinal Disord Tech 2008; 21:229-234.

69. Cloward RB. Posterior lumbar interbody fusion updated. Clin Orthop Relat Res 1985; (193):16-19.

70. Verbiest H. Pathomorphologic aspects of developmental lumbar stenosis. Orthop Clin North Am 1975; 6:177-196.

71. Kim HJ, Suh BG, Lee DB, Park JY, Kang KT, Chang BS, Lee CK, Yeom JS. Gender 
difference of symptom severity in lumbar spinal stenosis: Role of pain sensitivity. Pain Physician 2013; 16:E715-E723.

72. Fillingim RB, King CD, Ribeiro-Dasilva MC, Rahim-Williams B, Riley JL 3rd. Sex, gender, and pain: A review of recent clinical and experimental findings. J Pain 2009; 10:447-485.

73. Mannion AF, Junge A, Taimela S, Müntener M, Lorenzo K, Dvorak J. Active therapy for chronic low back pain: Part 3. Factors influencing self-rated disability and its change following therapy. Spine (Phila Pa 1976) 2001; 26:920-929.

74. Mannion AF, Wieser S, Elfering A. Association between beliefs and care-seeking behavior for low back pain. Spine (Phila Pa 1976) 2013; 38:1016-1025.

75. Shabat S, Folman Y, Arinzon Z, Adunsky A, Catz A, Gepstein R. Gender differences as an influence on patients' satisfaction rates in spinal surgery of elderly patients. Eur Spine ] 2005; 14:1027-1032.

76. Kim HJ, Suh BG, Lee DB, Lee GW, Kim DW, Kang KT, Chang BS, Lee CK, Yeom $J S$. The influence of pain sensitivity on the symptom severity in patients with lumbar spinal stenosis. Pain Physician 2013; 16:135-144.

77. Ishimoto Y, Yoshimura N, Muraki S, Yamada $\mathrm{H}$, Nagata K, Hashizume H, Takiguchi $\mathrm{N}$, Minamide $\mathrm{A}, \mathrm{Oka} \mathrm{H}$, Kawaguchi H, Nakamura K, Akune T, Yoshida
M. Prevalence of symptomatic lumbar spinal stenosis and its association with physical performance in a populationbased cohort in Japan: The Wakayama Spine Study. Osteoarthritis Cartilage 2012; 20:1103-1108.

78. Wang YX, Griffith JF, Ma HT, Kwok AW, Leung JC, Yeung DK, Ahuja AT, Leung PC. Relationship between gender, bone mineral density, and disc degeneration in the lumbar spine: A study in elderly subjects using an eight-level MRI-based disc degeneration grading system. Osteoporos Int 2011; 22:91-96.

79. United States Bone and Joint Initiative. The Burden of Musculoskeletal Diseases in the United States, 2nd ed. American Academy of Orthopaedic Surgeons, Rosemont, IL, 2011.

8o. Lehto MU, Honkanen P. Factors influencing the outcome of operative treatment for lumbar spinal stenosis. Acta Neurochir (Wien) 1995; 137:25-28.

81. McCullen GM, Bernini PM, Bernstein $\mathrm{SH}$, Tosteson TD. Clinical and roentgenographic results of decompression for lumbar spinal stenosis. J Spinal Disord 1994; 7:380-387.

82. Loupasis GA, Stamos K, Katonis PG, Sapkas G, Korres DS, Hartofilakidis G. Seven- to 20-year outcome of lumbar discectomy. Spine (Phila Pa 1976) 1999; 24:2313-2317.
83. Vucetic N, Astrand P, Güntner P, Svensson $\mathrm{O}$. Diagnosis and prognosis in lumbar disc herniation. Clin Orthop Relat Res 1999; (361):116-122.

84. Strömqvist F, Ahmad M, Hildingsson C, Jönsson B, Strömqvist B. Gender differences in lumbar disc herniation surgery. Acta Orthop 2008; 79:643-649.

85. Gepstein R, Arinzon Z, Adunsky A, Folman Y. Decompression surgery for lumbar spinal stenosis in the elderly: Preoperative expectations and postoperative satisfaction. Spinal Cord 2006; 44:427-431.

86. Wise EA, Price DD, Myers CD, Heft MW, Robinson ME. Gender role expectations of pain: relationship to experimental pain perception. Pain 2002; 96:335-342.

87. Triebel J, Snellman G, Sandén B, Strömqvist F, Robinson Y. Women do not fare worse than men after lumbar fusion surgery: Two-year follow-up results from 4,780 prospectively collected patients in the Swedish National Spine Register with lumbar degenerative disc disease and chronic low back pain. Spine J 2017; 17:656-662.

88. Pochon L, Kleinstück FS, Porchet F, Mannion AF. Influence of gender on patient-oriented outcomes in spine surgery. Eur Spine ] 2016; 25:235-246. 
